\title{
0 GÊNERO SARGASSUM C. AG. (PHAEOPHYTA - FUCALES) NO LITORAL DO ESTADO DE SÃO PAULO, BRASIL
}

\author{
EDISON JOSE DE PAULA
}

Instituto de Biociências e Centro de Biologia Marinha, Universi dade de São Paulo, CP 11461 - 05499-São Paulo, SP.

\begin{abstract}
The genus Sargassum (Phaeophyta-Fucales) from the coast of the State of São Paulo, Brazil). Based on large samples of populations of Sargassum from the coast of São Paulo, 13 infrageneric taxa are refered for the region, for which only 5 had previously been mentioned. The following taxa are recognized: S. cymosum C. Agardh var. cymosum, S. cymosum C. Agardh var. nanum Paula \& Oliveira Fo, S. rigidulum Kuetzing, S. stenophyllum (Mertens) Martius, S. ramifolium Kuetzing, S. filipendula C. Agardh var. filipendula, S. filipendula C. Agardh var. montagnei (Bailey) Grunow, S. filipendula C. Agardh var. pinnatum Grunow, S. filipendula C. Agardh var. laxum J. Agardh, $S$. vulgare C. Agardh var. vulgare, S. vulgare C. Agardh var. foliosissimum (Lamouroux) J. Agardh, S. vulgare C. Agardh var. nanum v. nova, S. furcatum Kuetzing. Except for $S$. vulgare var. nanum, a new variety here described, delimitations of species and varieties recommended by recent literature related to the Western Atlantic were adopted, despite their taxonomical difficulties which are discussed in detail. All the infrageneric taxa are described and illustrated. A key for species and varieties is given, in order to facilitate their identification. The taxonomical criteria are critically discussed. An analysis of the morphology and sex of the receptacles is included, which has not been considered in the recent literature. In addition, data are provided for an uderstanding of the phenotypical variation involved in the taxonomical difficulties of the genus.
\end{abstract}

RESUMO - (0 gênero Sargassum C. Ag (Phaeophyta-Fucales) no litoral do Estado de São Paulo, Brasil). Com base em uma ampla amostragem das populaçoes de Sargassum no litoral do Estado de São Paulo, são referidos 13 táxons infragenéricos para a região, onde apenas 5 eram conhecidos anteriormente. Foram reconhecidos os seguintes táxons: S. cymosum C. Agardh var. cymosum, S. cymosum C. Agardh var. nanum Paula \& Oliveira Fo, S. rigidulum Kuetzing, S. stenophyllum (Mertens) Martius, S. ramifolium Kuetzing, S. filipendula C. Agardh var. filipendula, S. filipendula C. Agardh var. montagnei (Bailey) Grunow, S. filipendula C. Agardh var. pinnatum Grunow, S. filipendula C. Agardh var. laxum J. Agardh, S. vulgare C. Agardh var. vulgare, S. vulgare C. Agardh var. foliosissimum (Lamouroux) J. Agardh, S. vulgare C. Agardh var. nanum v. nova, S. furcatum Kuetzing. Excetuando-se a descrição de uma variedade nova, S. vulgare var. nanum, as circunscrições específicas e varietais da literatura recente para o Atlântico Americano foram mantidas, reconhecendo-se, entretanto, dificuldades na sua delimitação. Todos os táxons infragenéricos presentes na área foram descritos e ilustrados, apresentando-se, ainda, uma chave de identificação das espécies e variedades. Os critérios taxonômicos empregados na delimitação das espécies, incluindo-se uma análise da morfologia e sexualidade dos receptáculos, que não tem sido considerada pelos autores recentes, foram criticamente discutidos. Adicionalmente, são fornecidas informações visando uma compreensão das causas das variações fenotípicas, responsáveis pelas dificuldades taxonômicas do grupo.

Key words - Sargassum, taxonomical criteria, taxonomy. 


\section{INTRODUÇXO}

o gênero Sargassum foi estabelecido em 1820 por C. Agardh. A partir de então os trabalhos taxonómicos mais abrangentes foram os de J. Agardh (1889), Grunow (1915, 1916), Setchell $(1931,1933,1935,1936)$, Womersley (1954) e Yoshida (1983).

$$
\text { J. Agardh (1889) segregou o gênero Sargassum em } 5
$$

subgêneros : I Phyllotrichia, II Schizophycus, III Bactrophycus, IV Arthrophycus, e V Eusargassum, divididos ainda em seç̧ões, séries, tribos e subtribos. Grunow (1915, 1916), no maior tratamento monográfico já efetuado no gênero, seguiu basicamente - sistema proposto por J. Agardh e incluiu Anthophycus Kuetzing como um novo subgênero de Sargassum, atualmente reinterpretado na categoria de gênero (Jensen, 1974). Os trabalhos de Grunow são básicos na taxonomia do gênero, abrangendo todas espécies conhecidas na época (230), embora apresentem descrições sumárias e não incluam ilustrações.

Setche11 (1931,1933,1935,1936), revendo as espécies de Sargassum da região de Hong Kong, embora tenha adotado o sistema de J. Agardh como guia, e proposto apenas uma pequena alteração, teceu amplos comentários que demonstram bem a limitação deste sistema. As 1 imitaçós do sistema de Agardh podem ser verificadas, ainda, no trabalho de Womersley (1954) com espécies do subgênero Phyllotrichia que ocorrem na Austrália e de Yoshida (1983) com espécies do subgênero Bactrophycus do Japão.

o gênero é um importante componente da flora marinha das regiões tropicais e subtropicais de ambos hemisférios do globo (Fritsch 1945, Nizamuddin 1962, 1970), possuindo um númeroestimado de espécies variável entre 250 (De Wreede \& Jones 1973) e 400 (Yoshida 1983).

No Brasil, especialmente na região sudeste, as populações de sargassum formam densas coberturas que se iniciam próximo ao 1 imite inferior da região entre marés nos costões rochosos. As interaçóes ecológicas nessas comunidades são pouco conhecidas, mas sua importancia pode ser inferida dos estudos sobre diatomáceas epifitas (Moreira Fo 1959, Kutner 1961, Moreira Fo \& Oliveira Fo 1976 e Rocha-0liveira 1980) e da fauna vágil e séssil associada (Lima 1969, Borojevic 1971, Pereira-Leite 1976, Pires 1975, Mountouchet 1979 e Tararam \& Wakabara 1981). Okuda et al. (1984), Tsukidate (1984), Umezaki (1984) e Yamauchi (1984), por outro 1ado, destacam a importância dos bancos de Sargassum no Japão onde são chamados "garamoba" e associados a uma maior produtividade de recursos pesqueiros.

As referências taxonômicas do gênero sargassum para o Brasil constam de listas de espécies ou de levantamentos floristicos regionais, sendo que poucas espécies foram cuidadosamente descritas e ilustradas. Para o litoral do Estado de São Paulo foram referidas três espécies e duas variedades (Joly 1957, 1965, Ugadim 1973, O1iveira Fo 1977 e Paula \& Oliveira Fo 1982). o conhecimento atual da taxonomia do gênero de uma maneira mais ampla para ot lântico Americano é largamente dependente dos trabalhos de Taylor, sintetizados em Taylor (1960), que foi seguido pelos autores recentes.

As dificuldades na delimitação das espécies do gênero são amplamente reconhecidas na literatura. Parr (1939) menciona que a comparação de espécies provenientes de ampla área de dis- 
tribuição mostra intergradações mais ou menos completas e questiona se estas intergradações são decorrentes de modificações paralelas de linhagens filogeneticamente distintas ou expressam uma continuidade genética, através de variações locais. Fritsch (1945) acredita, com base na multiplicidade de espécies pouco definidas, que o gênero sargassum é relativamente recente e ainda em curso de "vigorosa evolução". Taylor (1960), Earle (1969), Bertossi e Ganesan (1973) e 0liveira Fo (1977) chamam a atenção para as modificações morfológicas em função das condições ambientais. Taylor (1960) salienta que embora os caracteres descritivos sejam numerosos, são muito variáveis. Atribui essa variação a fatores ambientais e suspeita, em alguns casos, da possibilidade de hibridação. Earle (1969) questiona se as diversas formas são geneticamente distintas ou se devidas a plasticidade fenotípica. 01 iveira Fo (1977) chama a atenção para a necessidade de uma abordagem experimental.

A necessidade de um novo tratamento monográfico do gênero, baseado em coleções de tipos e plantas na natureza, tem sido lembrada, entre outros, por De Wreede e Jones (1973). Setchell (1936), entretanto, considerou, já naquela época, a necessidade de uma ampla experiência com grandes séries de plantas, bem como de estudos de variação, desenvolvimento e relações ecológicas, para se chegar a uma opinião bem substanciada do gênero.

As consideraçóes de Setchell (1936) e a importância ecológica do gênero justificam a necessidade de estudos sobre sua taxonomia, biologia e autoecologia. Neste contexto, o presente trabalho é parte de um estudo desenvolvido (Paula 1978), dentro de um programa de trabalho, visando um conhecimento integrado desses aspectos (Oliveira Fㅇ \& Paula 1979, Paula \& Oliveira Fo 1980, Paula \& 01iveira Fo 1982 e Paula 1984). Neste trabalho, os táxons infragenéricos presentes na área foram descritos e ilustrados com base em uma ampla amostragem em numerosas estações de coleta, procurando-se indicar as dificuldades encontradas para sua delimitação. Dentre os critérios taxonômicos, inclui-se uma análise da morfologia e sexualidade dos receptáculos, que não foi considerada pelos autores recentes.

De uma maneira geral, foram mantidas aqui as circunscrições específicas e varietais encontradas em Taylor (1960, 1976). Excetuam-se a estes casos, s. cymosum var. nanum, descrito por Paula e 01 iveira Fo (1982) e a descrição de uma variedade nova de S. vulgare.

Adicionalmente, procurou-se fornecer elementos considerados relevantes para o possivel entendimento das causas da variabilidade nas populações naturais, responsável pelas dificuldades taxonômicas do grupo.

\section{A REGIÃO ESTUDADA}

O litoral do Estado de São Paulo possui uma linha costeira com cerca de $600 \mathrm{~km}$, que se estende na direção $\mathrm{SW}-\mathrm{NE}$ e está compreendida entre 25013's - 48.00'W e 23021's - 44043'W (Fig. 1). Desse total, cerca de um terço corresponde a costões rochosos. Com base na proporção de costões rochosos, extensão das praias e características de exposição ao mar aberto podem ser discernidas 3 sub-regiões (01iveira Fo \& Paula 1979). 


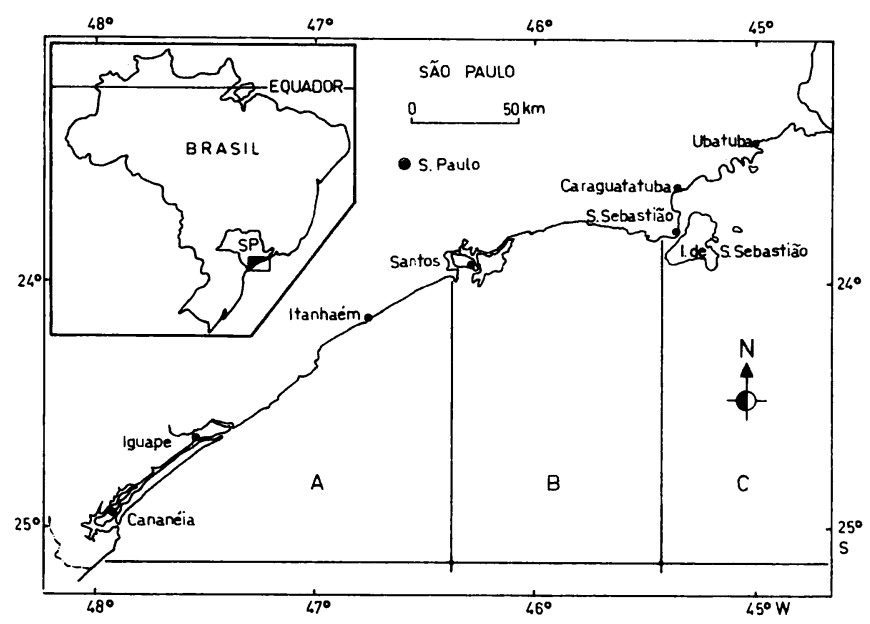

Fig. 1 - Localização da região estudada e das sub-regiões: A - Sudoeste; B Central; C - Nordeste. (Mapa adaptado de Emilson et al. 1963).

Fig. 1 - Surveyed area with the 3 main regions: A - Southwest; B - Central; $C$ - North-east. (Map adapted from Emilson et al. 1963).

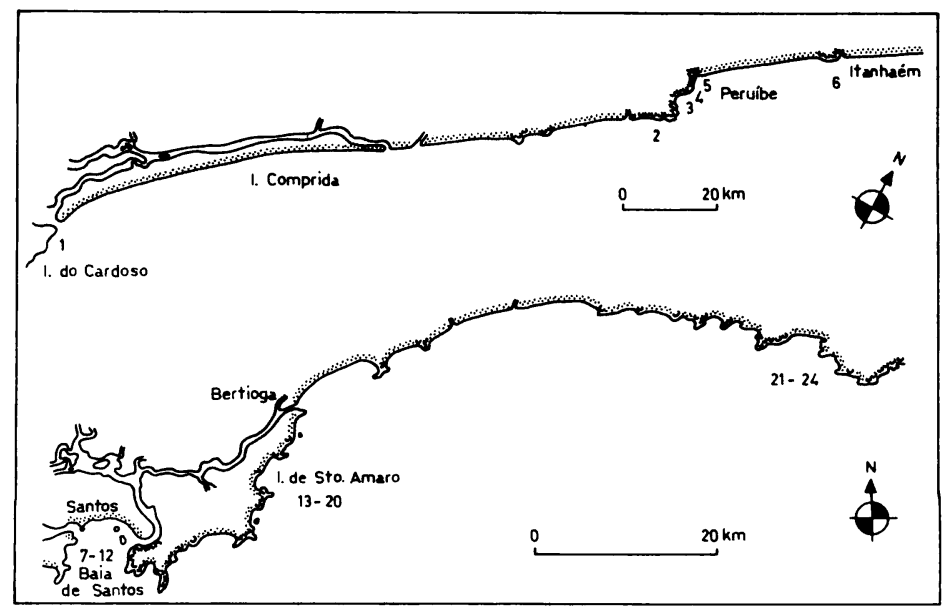

Fig. 2 - Sub-regiões Sudoeste e Central. Localização das estações de coleta. (Mapa superior da figura adaptado de Joly 1965 e o inferior de Silva 1952). A denominação das estações de coleta encontra-se na Tabela 3.

Fig. 2 - Southwest and Central regions. Localization of the sampling sites (Upper and lower maps adapted respectively from Joly 1965 and Silva 1952). Local names are listed in Table 3. 
A. Região Sudoeste - estendendo-se da Ilha do Cardoso, Município de Cananéia, à Praia do Boqueirão, no Municipio da Praia Grande, com pequenos costões rochosos, na maioria diretamente voltados para o mar aberto e que somados dão uma extensão de cerca de $26 \mathrm{~km}$, separados por extensas praias arenosas e manguezais (Figuras 1 e 2 ).

B. Região Central - estendendo-se da Praia do Boqueirão à Praia de Barequeçaba, no Município de São Sebastião, com uma baía poluída (Baía de Santos) e uma extensa linha costeiradiretamente voltada para o mar aberto, com cerca de $77 \mathrm{~km}$ de costões rochosos (Figuras 1 e 2 ).

C. Região Nordeste - estendendo-se da Praia de Barequeçaba à Ponta da Trindade, no Município de Ubatuba, com numerosas enseadas, onde os costões variam bastante quanto à extensão e grau de exposição ao mar aberto somando no total cerca de $93 \mathrm{~km}$ (Figuras 1 e 3 ).

bem como uma localização mais detalhada das estações de coleta, em Paula (1978).

\section{MATERIAL E METODOS}

0 material examinado foi proveniente de 72 estações de coleta ao longo do litoral do Estado de São Paulo (Figuras 1-3). As coletas foram concentradas na sub-região nordeste, dado que esta mostrou-se mais rica em relação às outras duas. Em cada estação, os costões rochosos foram percorridos desde seus pontos mais protegidos aos mais expostos à ação das ondas, tendo-se tomado amostras em grande número para avaliar as variações morfológicas intra-populacionais e correlacionar, tentativamente, a distribuição geral dos táxons. O grau de exposição às ondas de cada local amostrado foi avaliado empiricamente, tendo sido auxiliado pela anotação das espécies que segundo Joly (1957) e oliveira Fo e Mayal (1976) são indicadoras dos costões mais expostos.

o sexo dos talos foi analisado na grande maioria das plantas através de cortes transversais e longitudinais aos receptáculos.

Todo material estudado encontra-se depositado no Herbário (SPF), do Departamento de Botânica do Instituto de Biociências da USP. Além do material coletado foram analisadas as coleções anteriores, existentes neste herbário e no Herbário SP, do Instituto de Botânica da Secretaria de Agricultura e Abastecimento do Estado de São Paulo. Embora tenham sido analisadas, comparativamente, exsicatas provenientes de outras regiões do Brasil e do exterior, constam da relação do material estudado, somente aquelas provenientes da área de estudos. Por brevidade, nãomencionamos os nomes dos coletores. Todo material datado a partir de 1975 foi coletado especificamente para a elaboração deste trabalho. Como referências, foram incluidos todos os autores que citam o táxon para o Brasil, mesmo que não o descrevam, e alguns autores selecionados que tratam da flora de outras regióes, quando apresentam descrições e ou ilustrações, ou ainda, quando consideradas importantes para um melhor entendimento do táxon em questão. 


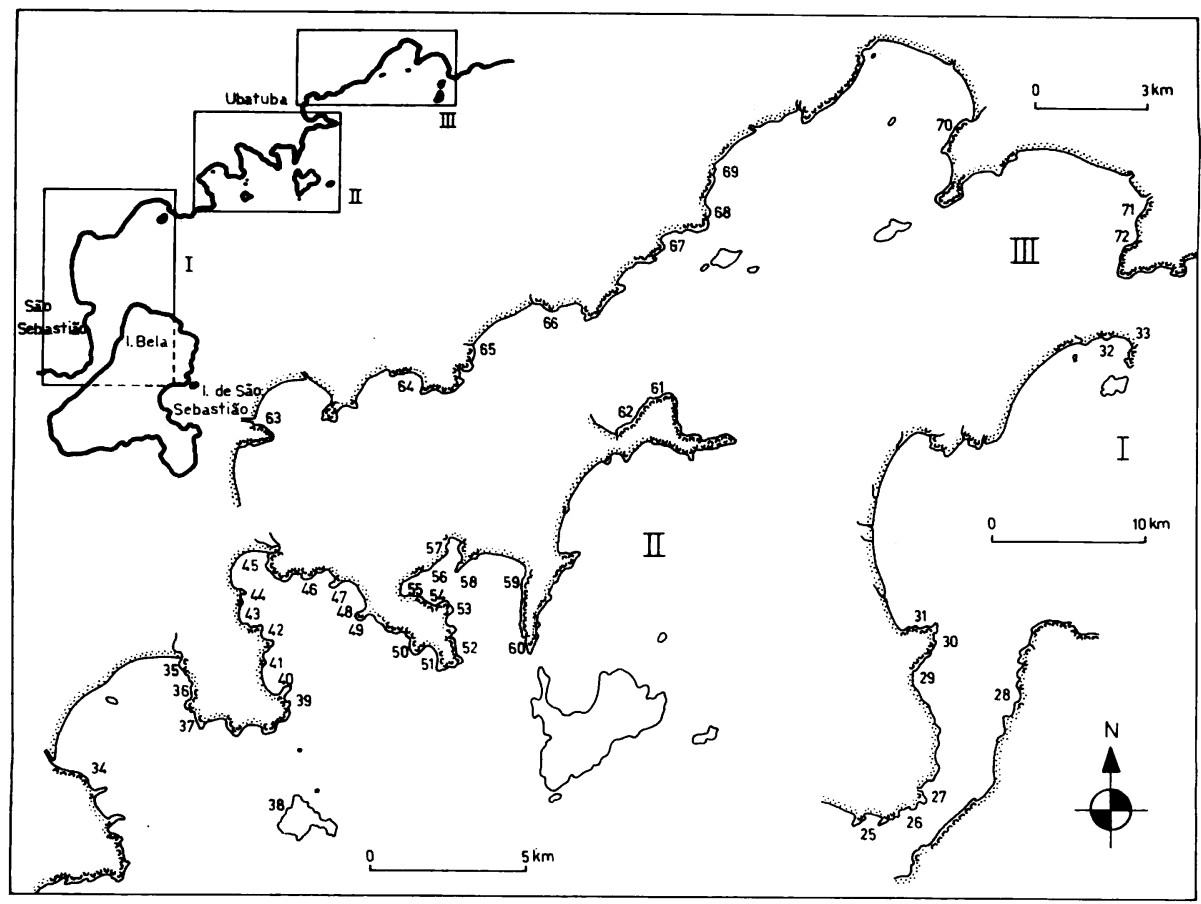

Fig. 3 - Sub-região Nordeste. Localização das estações de coleta (Mapas à esquerda da figura adaptados de Joly 1965, os da direita, superior e inferior, respectivamente, de Cruz 1974 e Kvinge 1967). A denominação das estações de coleta encontra-se na Tabela 3.

Fig. 3 - North-east region. Localization of the sampling sites (Maps on the left adapted from Joly 1965, on the right, upper and lower maps adapted from Cruz 1974 and Kvinge 1967, respectively). Local names are listed in Table 3.

\section{RESULTADOS}

\section{Morfologia Geral}

As plantas de Sargassum, subgênero Eusargassum, são formadas basicamente por um apressório, eixos principais e ramos laterais primários (Figura 4). O apressório é disciforme, sendo constituído por filamentos compactamente sobrepostos e entrelaçados. Do apressório partem numerosos eixos principais cilíndricos, rugosos, comumente muito reduzidos, atingindo no máximo cerca de $6 \mathrm{~cm}$ de comprimento; simples ou raramente ramificados. No ápice dos eixos principais diferenciam-se contínua e radialmente os ramos laterais primários que constituem a maior parte do sistema vegetativo. Os ramos laterais primários assemelham-se aos siste- 
mas caulinares das traqueófitas. Consistem de um eixo cilíndrico de crescimento indefinido, que porta espiraladamente, às vezes em posição alterno-dística, ramos laterais laminares de crescimeto definido, semelhantes às folhas das angiospermas, possuindo uma nervura central. 0 termo folha é empregado em seu sentido descritivo, em que pese o fato delas não serem homólogas às folhas das plantas vasculares (Setche11 1933, Fritsch 1945, Jensen 1974).

As folhas podem ser simples ou ramificadas, lanceoladas a lineares, planas ou mais ou menos onduladas com bordo serreado ou liso. Na axila das folhas diferenciam-se ramificaçoes de ordem mais elevada, flutuadores ou receptáculos.

os flutuadores são estruturas esféricas ou elípticas ocas, terminadas ou não por um apiculo ou por uma expansãofoliar; ocorrem na extremidade de um pediculo cilindrico, levemente achatado ou expandido em forma de folha.

Os receptáculos consistem de um sistema de ramos cilíndricos ricamente ramificados, contendo os elementos de reprodução situados em conceptáculos. Nas plantas unissexuais, os receptáculos masculinos são facilmente distinguíveis dos femininos, mesmo a olho nu e em, condições naturais, no campo. Nas plantas bissexuais, os receptáculos apresentam conceptáculos unissexuais lado a lado, são geralmente menores e possuem ramificações mais densamente agrupadas que os receptáculos masculinos e femininos.

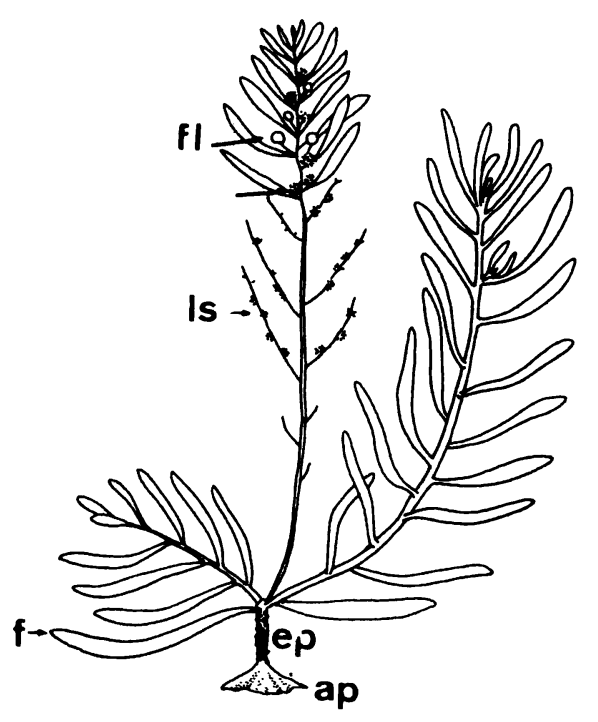

Outras estruturas de
grande importancia no
genero e que, juntamente
com os conceptáculos,
constituem uma das prin-
cipais caracteríticas
da ordem Fucales são os
criptostomas. Ambas são
cavidades imersas no ta-
lo, com um poro de comu-
nicaça ao meio externo,
sendo que, os criptosto-
mas contem apenas tufos
de pêlos. os criptosto-
mas ocorrem em diferen-
tes arranjos nas folhas,
aparecem, ainda, nos
flutuadores e nos ramos
cilindricos e aqui podem
ser alongados, com bordo
ligeiramente saliente ou
projetando-se como um
espinho.

Fig. 4 - Esquema da organização de uma planta de Sargassum, onde foi representado: ap - apressório; ep - um único eixo principal; 1p - 3 ramos laterais primários em diferentes estágios de desenvolvimento; 1s - 1aterais secundários (desnudos); f - folhas; fl - flutuadores e $\mathrm{r}$ - receptáculos.

Fig. 4 - Schematic representation of the organization of thallus of Sargassum: ap - holdfast; ep - main axis; $1 p$ - 3 primary laterals; $1 s$ - secundary laterals (denuded); $f$ - leaves, $f l$ - bladders and $r$ - receptacles. 


\section{Critérios taxonômicos}

Os táxons infragenéricos de Sargassum que ocorrem no litoral do Estado de São Paulo e seus caracteres taxonômicos mais típicos encontram-se na Tabela 1 .

As plantas mais características de cada táxon crescem em condições um tanto particulares de exposição as ondas e profundidade e possuem hábito e comprimento, compreendidos numa faixa de valores, que podem ser considerados como típicos.

Se levarmos em conta as dimensões do talo, grau e tipo de ramificação dos ramos laterais primários e outras características, podemos distinguir 5 tipos morfológicos, como na Figura 5. Tipo I - Talo firme, erecto, mesmo quando emerso. Não ultrapassa $10 \mathrm{~cm}$ de comprimento; possui numerosos ramos principais e laterais primários não ramificados; apressório bem desenvolvido e flutuadores ausentes. Tipo II - Talo flexível, movimentado pelas ondas, com 20 a $40 \mathrm{~cm}$ de comprimento; possui laterais primários não ramificados. Tipo III - Talo flexível, movimentado pelas ondas, com 20 a $40 \mathrm{~cm}$ de comprimento; possui laterais primários com ramificações de primeira ordem. Tipo IV - Talo erecto, firme, com 20 a $40 \mathrm{~cm}$ de comprimento; possui laterais primários com ramificações de primeira e segunda ordem. Tipo V - Talo com 50 a $70 \mathrm{~cm}$ de comprimento; possui poucos ramos principais e laterais primários com ramificações de primeira ordem longas e afastadas umas das outras.

Estes tipos morfológicos podem ser relacionados, empiricamente, a determinadas condições de movimentação da água e profundidade onde ocorrem.

0 tipo morfológico I ocorre nos costões diretamente voltados para o mar aberto, extremamente batidos, expondo-se ao ar nas marés baixas. o tipo il ocorre mais comumente em costones moderadamente batidos, mas pode ser encontrado em costões diretamente voltados para o mar aberto (S. rigidulum), ficando ou não exposto ao ar nas marés baixas. 0 tipo III ocorre mais comumente em costões moderadamente protegidos, ficando ou não exposto ao ar nas marés baixas. 0 tipo IV ocorre mais comumente nos costões protegidos a moderadamente protegidos, sempre submerso. No tipo v podemos reconhecer duas condições peculiares: ocorre nos constões extremamente protegidos, sempre submerso, sustentado em posição erecta pelos flutuadores, com a porção superior do talo visível ou não nas marés baixas; ocorre nos costóes caracterizados pela incidência de grandes ondas, mas sem impacto direto, produzindo, dessa maneira, um fluxo lateral de água, isto é, uma correnteza. os talos são flexíveis e permanecem grande parte do tempo em posição inclinada, ficando, ou não expostos nas marés baixas.

$\mathrm{Na}$ Tabela 2 estão relacionados os tipos morfológicos que ocorrem nos diferentes táxons. Sua análise revela que os táxons examinados diferem quanto a amplitude de variação desse caráter, sugerindo plasticidade fenotípica.

A análise dos tipos morfológicos, em associação com a presença ou ausência dos flutuadores e com as variações da morfologia, dimensões e sexualidade dos receptáculos ( Tabelas 1-3), por outro lado, sugere diferenças genotípicas. Os flutuadores estão ausentes nas populações de costão extremamente batido (tipo morfológico I), mas nos costões protegidos podem ser muito abun- 


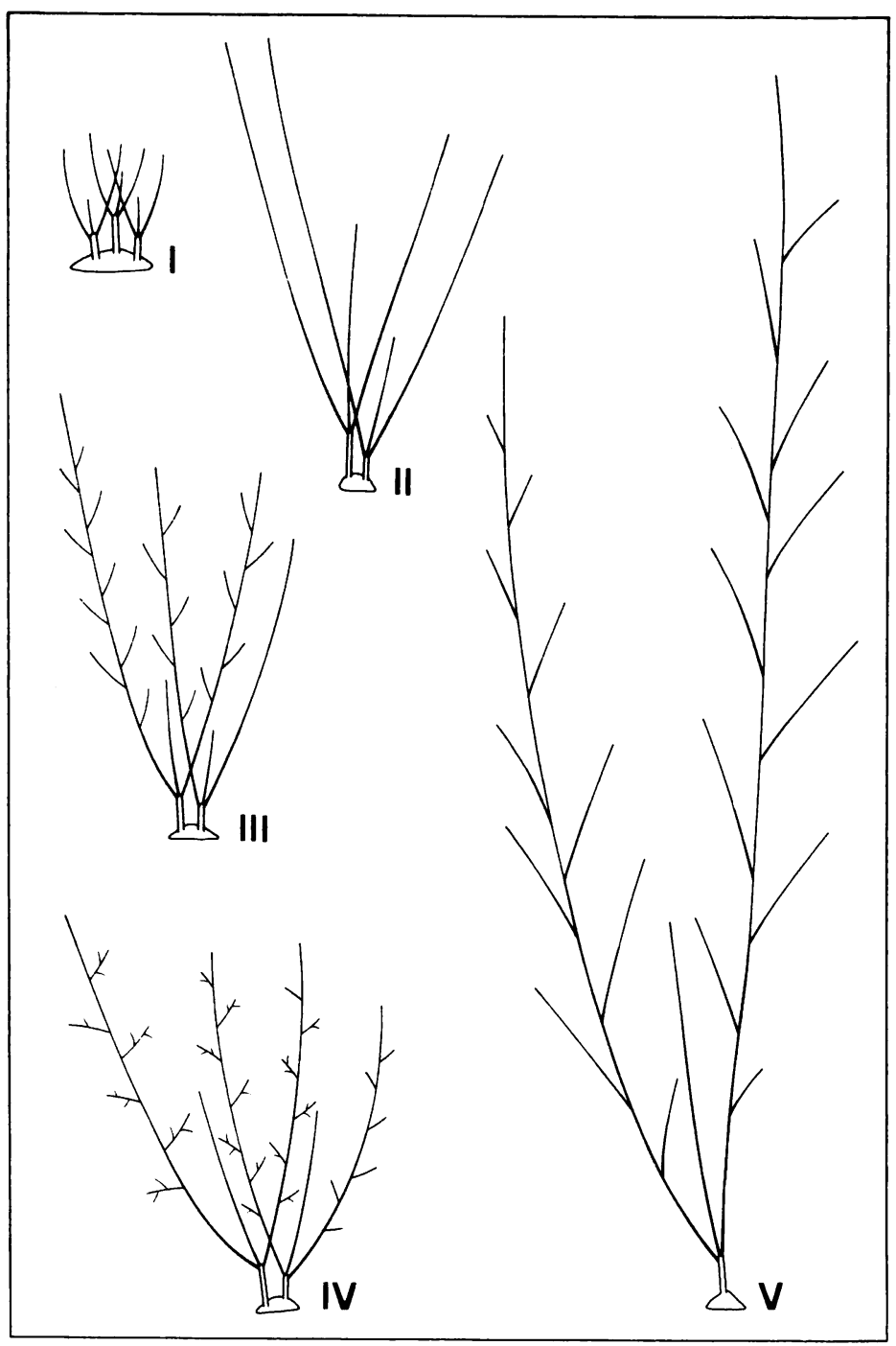

Fig. 5 - Tipos morfológicos estilizados de Sargassum, reconhecidos especialmente com base nas dimensões do talo, grau e tipo de ramificação dos ramos laterais primários (ver texto). Obs.: não foram representadas as folhas, flutuadores e receptáculos.

Fig. 5 - Morphological types of Sargassum based specially on dimensions of the thallus, degree and kind of branching of the primary laterals (see text). obs.: Leaves, bladders and receptacles are not represented. 




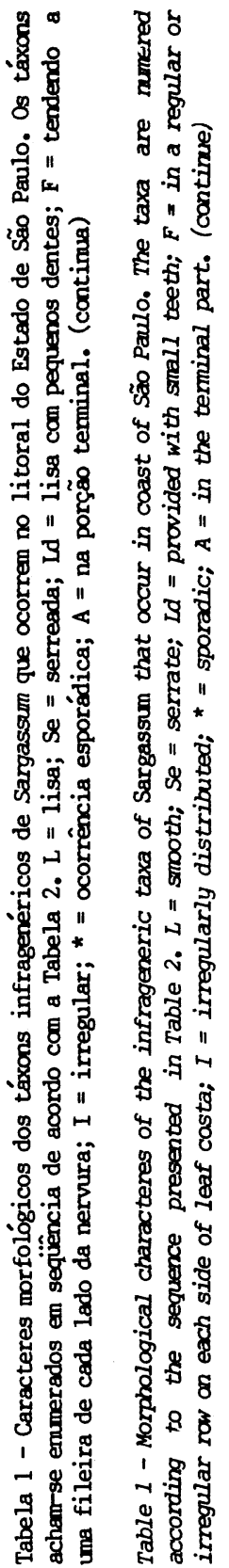




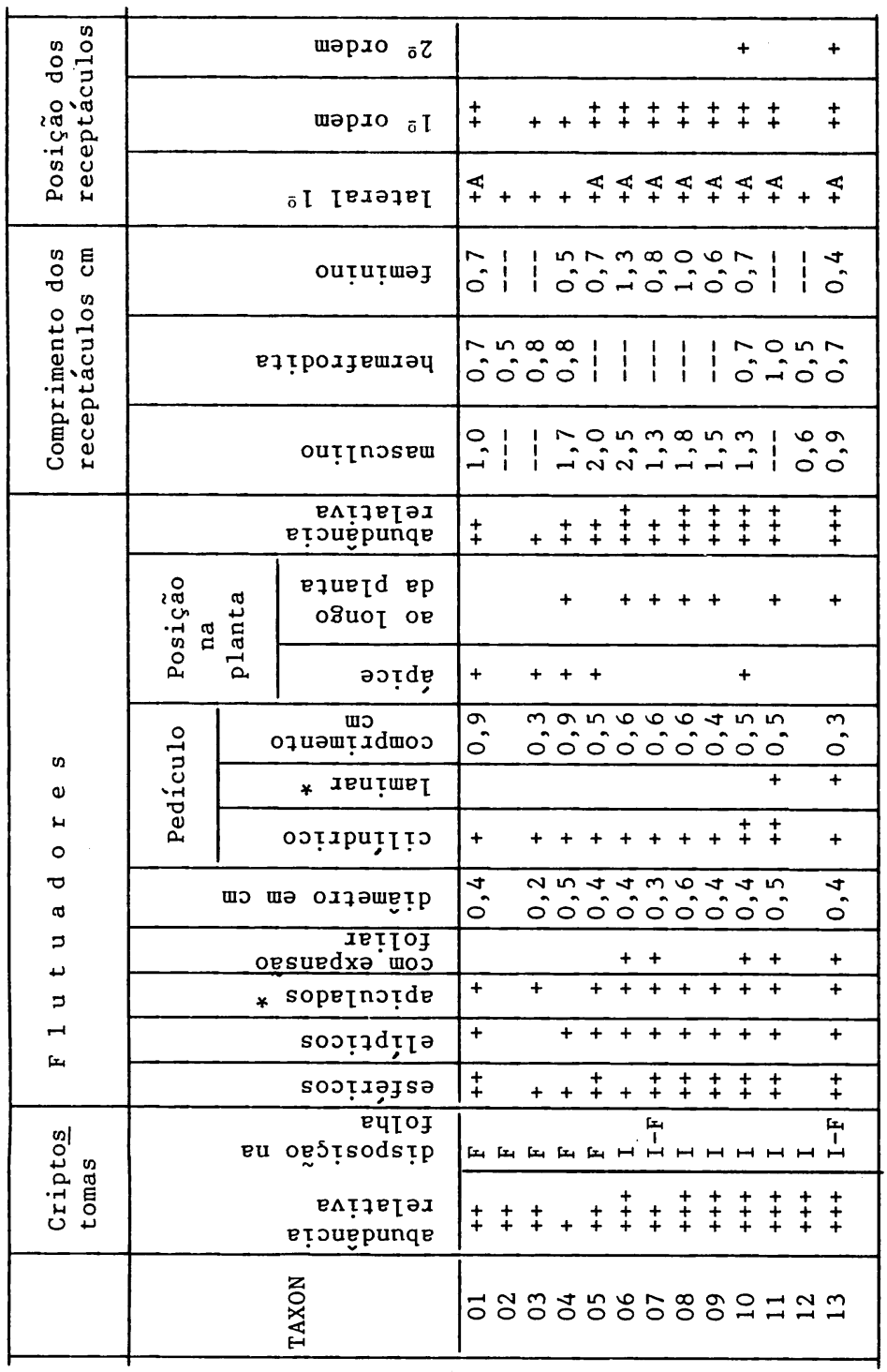

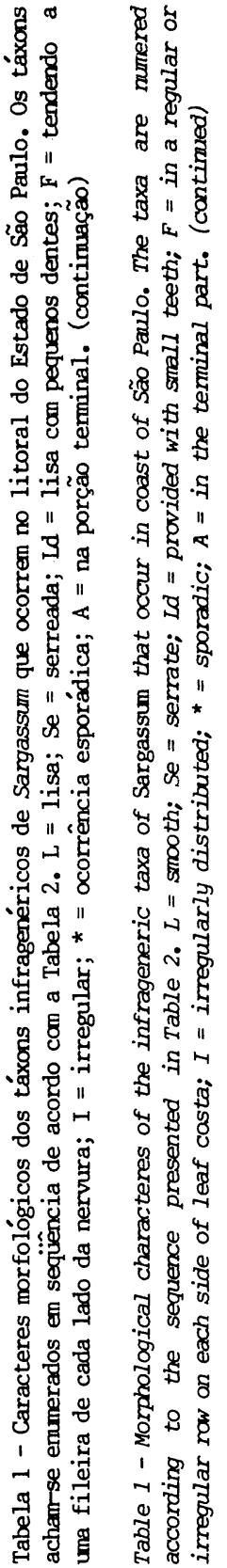




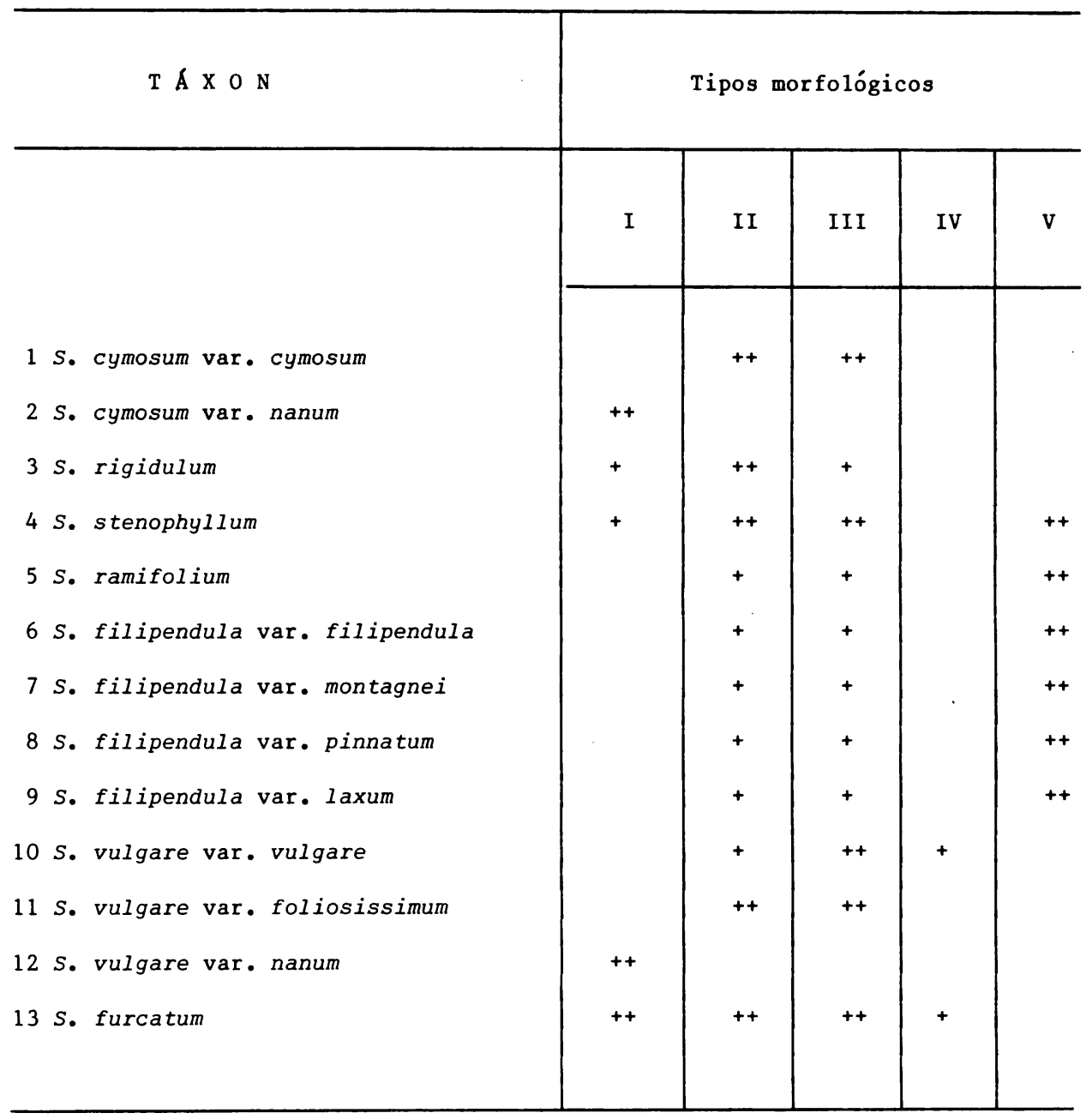

Tabela 2 - Ocorrência dos tipos morfológicos de Sargassum, como definidos na figura 5, nos táxons infragenéricos que ocorrem no litoral do Estado de São Paulo.

Table 2 - Occurrence of morphological types of Sargassum defined in figure 5 for the infrageneric taxa that occur in the coast of São Paulo. 


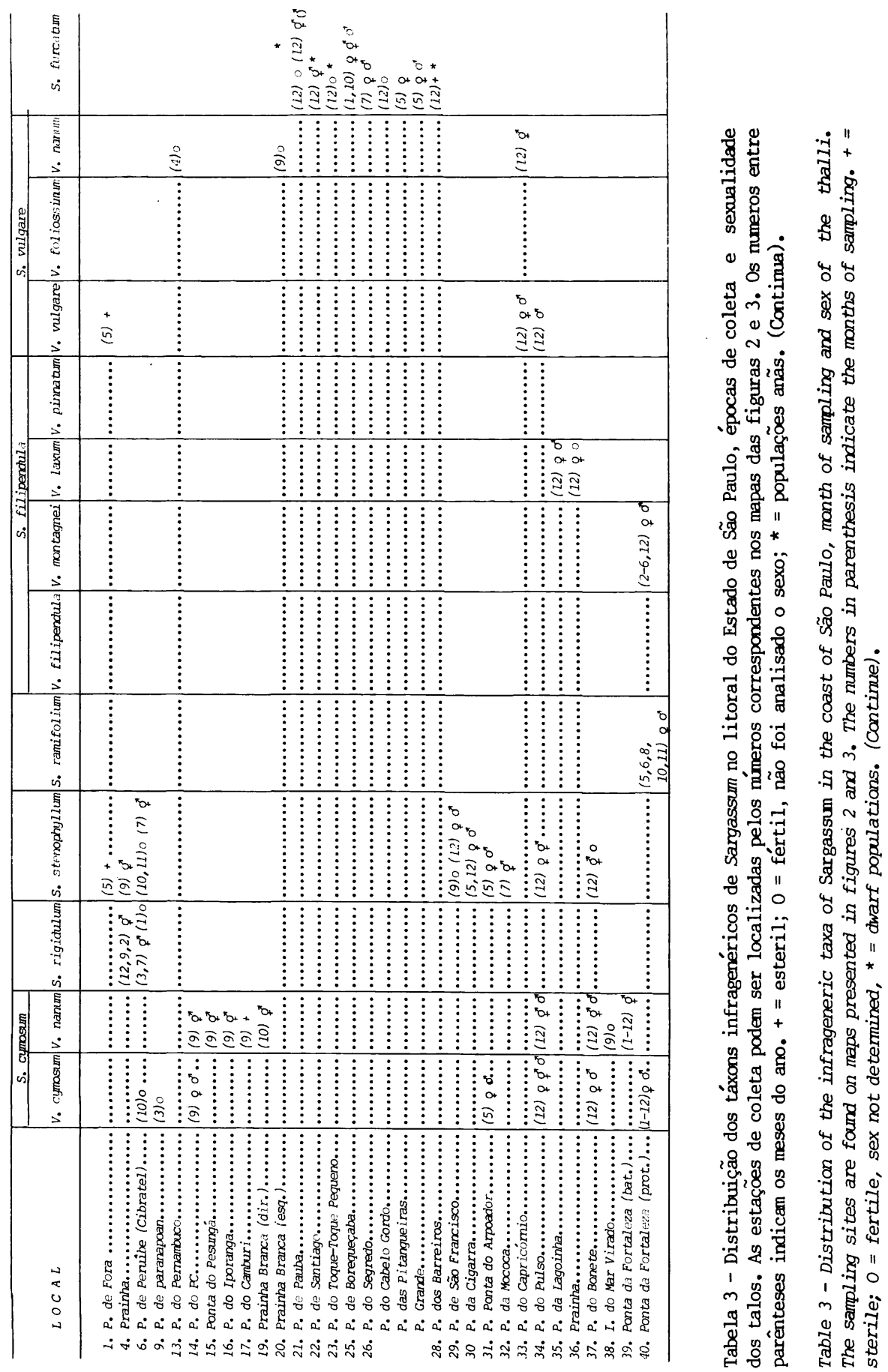




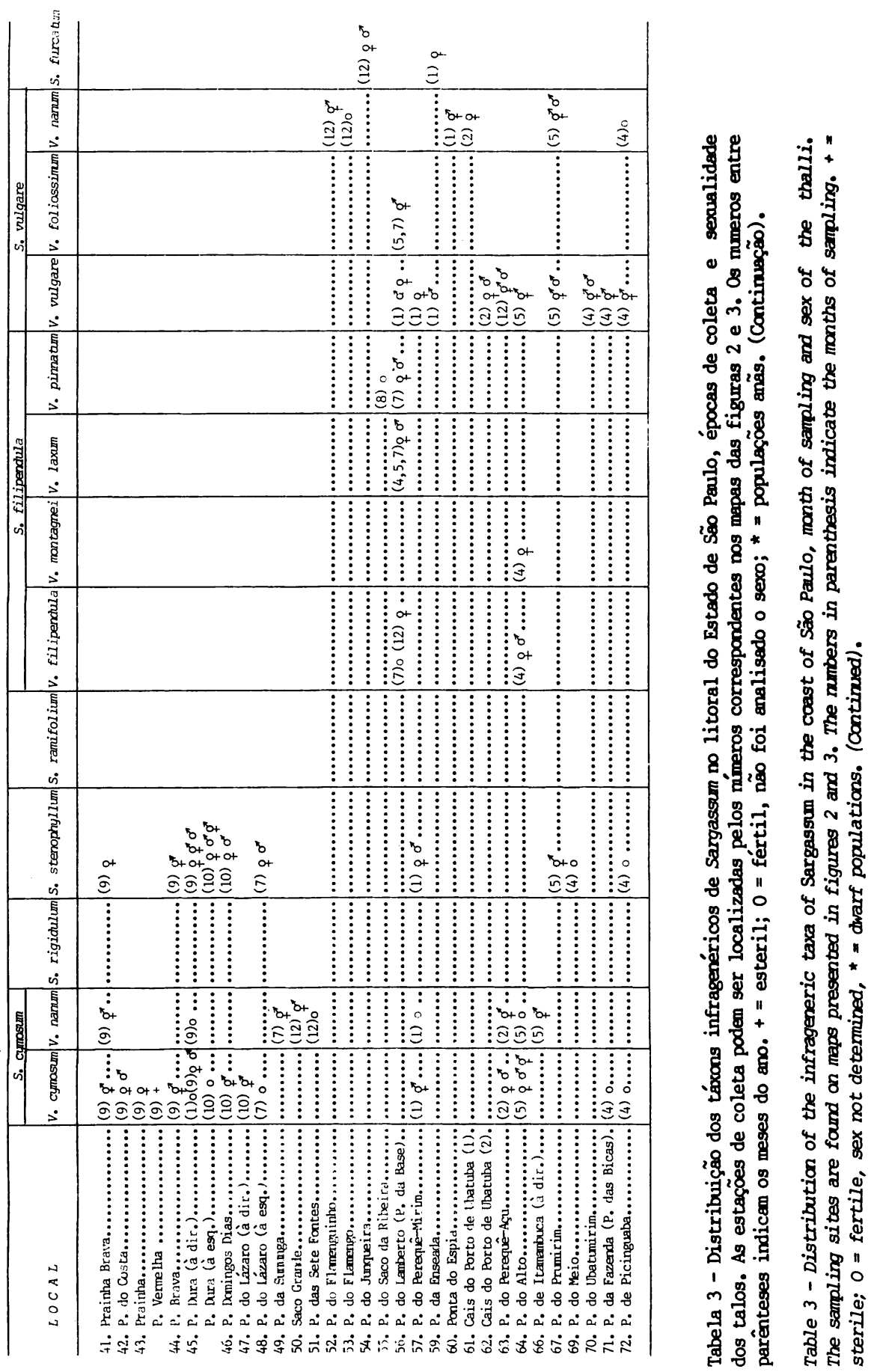


dantes ou faltarem em exemplares crescendo lado a lado, sugerindo que a presença ou não de flutuadores seja geneticamente determinada, mas que sua freqüência nas populaçöes está sujeita a seleção ambiental.

o tipo morfológico I é próprio de plantas que podem ser consideradas anãs, sendo caracterizadas por receptáculos geralmente bissexuais. No outro extremo, as plantas de costões mais protegidos são geralmente unissexuais. Em outras circunstâncias, ocorrem populações mistas de plantas unissexuais e bissexuais, com a predominância de uma ou de outra condição, sugerindo, da mesma maneira, diferenças genotípicas cuja freqüência seria sujeita a seleção ambiental.

0 tipo morfológico I foi verificado em plantas relacionadas a s. cymosum, s. vulgare, s. furcatum, s. rigidulum e s. stenophyllum. Populações de plantas anas relacionadas a $S$. cymosum, S. vulgare e s. furcatum, formando faixas verticalmente estreitas nos costões extremamente batidos e crescendo em nível mais elevado que as populações de costão protegido, ocorreram em 18,9 e 4 estações de coleta, respectivamente (Tabela 3). Em muitas circunstâncias as populações de plantas anas ocorreram geográfica ou ecologicamente isoladas das populações de costão protegido, sugerindo diferenciação ecotípica (ver comentários para estas espécies). Os resultados de estudos experimentais de transplante e cultivo em laboratório com $S$. cymosum e $S$. vulgare (Paula \& 0liveira Fo 1982, Paula 1984) corroboram esta interpretação. S. rigidulum e s. stenophyllum, por outro lado, possuem ramos laterais primários não ramificados ou com ramificações escassas e dispostas em ângulo agudo, de maneira que os tufos são geralmente afilados e flexíveis, oferecendo, possivelmente, menor resistência mecânica ao fluxo da água. As duas espécies podem atingir maiores dimensões mesmo nos locais mais expostos, excetuando-se os exemplares próximos ao limite superior de sua zona vertical de distribuição que podem ser anões. plantas anãs relacionadas e estas espécies foram raras, ocorrendo em poucos locais e sem uma descontinuidade populacional. Com relação à sexualidade, as plantas de S. rigidulum sempre apresentaram receptáculos bissexuais, mesmo aquelas com maiores dimensões, dos costões mais protegidos. S. stenophyllum, por outro lado, mostrou acentuadas variações, onde, mesmo nas populações de plantas grandes, ocorreram, dependendo do local, somente plantas unissexuais, somente bissexuais e ainda populações mistas de plantas bissexuais e unissexuais femininas e/ou masculinas. A ausencia de uma descontinuidade abrupta com relação aos tipos morfológicos e sexualidade dos receptáculos sugere, neste caso, variações clinais para estes caracteres, relacionados ao grau de exposição às ondas.

Em adição às variações fenotípicas em resposta ao ambiente descritas acima, podem ser reconhecidas variaçóes ontogênicas e variações individuais intra e interpopulacionais.

As folhas dos ramos jovens, surgindo próximas a base das plantas, possuem dimensões muito superiores àquelas da porção terminal dos ramos, especialmente se estes se encontram férteis. S. Stenophyllum, por exemplo, reconhecido por suas folhas muito estreitas, com $1-(2)-3 \mathrm{~mm}$ de largura (Tabela 1 ), pode apresentar folhas mais basais com até $10 \mathrm{~mm}$ de largura. Nos táxons com folhas ramificadas ( Tabela 1) estas são mais comuns no terço superior dos ramos, enquanto as folhas mais inferiores podem ser simples. 
A frequência de folhas ramificadas e o grau de ramificação, por outro lado, pode variar de espécime para espécime e entre populações diferentes. Podem ocorrer, ainda, em espécies com folhas simples, pelo menos em baixa freqüência. 0 mesmo pode ser verificado com relaça a margem das folhas que pode apresentar gradações entre lisa a serreada.

Criptostomas muito numerosos, com distribuição inrregular na superfície da folha, são característicos de certos táxons (Tabela l), mas podem ser menos numerosos e tendendo a uma fileira de cada lado da nervura em espécimes particulares ou em variedades desses mesmos táxons com folhas mais finas.

Eixos cilíndricos muriculados, com "espinhos" muito salientes, são característicos de $S$. furcatum (Tabela 1 ), mas ocorrem com frequência variável nesta espécie. Ocorreram ainda nos ramos jovens de $S$. ramifolium e $s$. filipendula, mas aqui apenas como ligeiras projeções. Mais raramente, projeções deste último tipo ocorreram em espécies com eixos lisos como $S$. vulgare, $S$. rigidulum e s. stenophyllum.

A morfologia, abundâcia relativa, posição na planta e as dimensões dos flutuadores, mais que quaisquer outras características, não podem ser avaliadas com base em poucos exemplares. São geralmente esféricos e destituídos de projeção terminal, mas podem ser encontrados elípticos, apiculados ou terminados por uma expansão foliar num mesmo espécime (Tabela 1). Da mesma forma, o pedículo, pelo qual os flutuadores são sustentados, é geralmente cilíndrico mas pode apresentar-se ligeiramente achatado ou laminar.

A morfologia e dimensões dos receptáculos são largamente dependentes do sexo dos mesmos. 0 padrão básico de ramificação dos receptáculos de todos os táxons analisados é do tipo racemo. A aparência dicotômica, inclusive utilizada nas descrições de algumas espécies, parece ser secundária e devida ao fato de que as ramificações laterais surgem muito próximas ao ápice dos receptáculos. Na realidade, nem sempre pode-se distinguir adequadamente um receptáculo ramificado de um ramo receptacular, isto porque a presença de um pedículo estéril, que permitiria tal distinção, ocorre em variados graus, estando na dependência do estágio de desenvolvimento. A presença de uma folha basal, da mesma forma, nem sempre pode ser tomada como uma referência segura e, por esse motivo, para as descrições, ilustraçóes e medidas, foram utilizados receptáculos (ou ramos receptaculares) bem desenvolvidos da axila das folhas dos laterais primários.

A comparação da morfologia dos receptáculos, entre os diferentes táxons, revela grandes diferenças quanto às dimensões e forma, mas condições transitórias também não faltam. De qualquer manejra, não se pode distinguir perfeitamente dois tipos de receptáculos, um com ramificaçóes dicotômicas e outro com ramificações do tipo racemo.

Em todos os táxons, com exceção de $S$. vulgare var. foliosissimum, somente conceptáculos unissexuais foram encontrados. Nessa variedade, embora os conceptáculos unissexuais fossem mais comuns, também foram encontrados conceptáculos bissexuais.

A variabilidade com o qual se manifestam esses e outros caracteres dificulta em parte o reconhecimento de cada táxon, mesmo quando as espécies envolvidas são muito distintas. S. ramifolium, por exemplo, é muito distinto de $S$. furcatum, no entanto 
algumas plantas daquela espécie, que crescem em níveis mais elevados do costão são menores, possuem folhas menores e por isso podem ser, pelo menos a primeira vista, confundidas com algumas plantas desta. Plantas típicas de $S$. filipendula var. montagnei não apresentam dificuldade alguma para serem distinguidas de $S$. vulgare. No entanto, verificamos que algumas plantas, que não podem ser separadas daquela variedade em função de sua distribuição local e padrão de variação contínua, possuiam folhas mais curtas e mais largas e podem ser confundidas com esta. Estas dificuldades são ampliadas quando as espécies envolvidas são afins (ver comentários para $S$. furcatum).

A variação sazonal das características morfológicas pode ser responsável, em parte, pelas dificuldades encontradas. Na Praia da Fortaleza os exemplares de $S$. cymosum, coletados io verão possuiam maior número de ramos velhos e conseqüentemente maior freqüencia de folhas menores, mais curtas e mais estreiras. o mesmo ocorreu com $S$. vulgare coletado no verão na Baía do Flamengo. No entanto, sempre ocorreram ramos jovens, o que permitiu - reconhecimento da espécie. Exemplares de S. rigidulum coletados no verão na Prainha (Mun. de Peruíbe) apresentavam folhas com pequenos dentes, e eixos ligeiramente muriculados, em confronto com os espécimes coletados no mesmo local na primavera, com folhas e eixos lisos.

Uma das maiores dificuldades na delimitação surge quando dois ou mais táxons convivem numa área. Neste caso, fica difícil distinguílos claramente, devido a existência freqüente, de individuos com características intermediárias. A presença destes individuos não ocorre somente entre variedades, mas também entre espécies, às vezes morfologicamente muito distintas. Citam-se como exemplo $S$. stenophyllum e $S$. rigidulum na Praia de Peruíbe ("Cibratel" - Mun. de Itanhaém), S. cymosum e s. vulgare var. vulgare na Praia do Perequê -Assú, Praia da Fazenda e Praia de Picinguaba (Mun. de Ubatuba), s. cymosum var. cymosum, S. filipendula var. filipendula e s. vulgare var. vulgare na Praia do Alto (Mun. de Ubatuba) - (ver comentários em $S$. cymosum var. cymosum). Dessa forma, diferentes populações de uma mesma espécie mostram peculiaridades que as tornam, ora facilmente reconhecidas, ora difíceis de serem distinguidas de uma ou de outra espécie. Essas peculiaridades comumente estão relacionadas com as diferentes espécies com as quais convivem, sugerindo a possibilidade de hibridação em condições naturais.

Adicionalmente, exemplares de um mesmo táxon, mas provenientes de outras regiões do Brasil e de outros países, sempre revelam algumas variações peculiares.

Uma análise dos diversos aspectos da variabilidade considerados acima podem levar, perfeitamente, a suspeita da existência de um número reduzido de espécies para o litoral do Estado de São Paulo que, entretanto, apresentariam um alto grau de plasticidade fenotipica, a lado de variaçóes clinais que, em seu extremo, levaria a divergência genética de populaçóes localmente adaptadas (ecótipos). A interpretação sobre a hibridação entre espécies distintas, por outro lado, parece igualmente válida.

A existência de populações heterogêneas, apresentando espécimes com características transitórias, associada ao padrão geral de distribuição, poderia justificar o tratamento de algumas espécies a nível de variedade. Este é o caso, por exemplo, de 
S. stenophyllum e $S$. ramifolium que poderiam ser consideradas variedades de $S$. cymosum ou ainda, $S$. furcatum que poderia ser considerada uma variedade de $s$. vulgare. Condiderando as dificuldades na delimitação das espécies em geral e a necessidade de estudos em áreas geográficas mais amplas, preferimos adotar a circunscrição das espécies de acordo com a literatura recente parao At lântico Americano, em especial os trabalhos de Taylor (1960, 1976), Earle (1969) e Bertossi e Ganesan (1973). Dessa forma, as espécies foram reconhecidas e delimitadas com base em conjuntos de caracteres ou pelo grau ou frequência elevados de certas caracteristicas.

As variedades anãs de $S$. cymosum e $S$. vulgare foram definidas considerando-se, além das diferenças morfológicas, sua distribuição e seu isolamento geográfico ou ecológico das variedades típicas. Nestes casos, a existência de populaçóes de transição em alguns locais, justificou o tratamento a nível de variedade. Consulte-se Paula e Oliveira Fe (1982) e Paula (1984) para maiores informações. Nesse sentido, essas variedades correspondem ao critério proposto por Davis e Heywood (1973) para facies 1ocais de uma espécie.

Com relação as outras variedades, pequena ou nenhuma evidência de diferenciação populacional foi encontrada. Esse é o caso em especial de $s$. filipendula var. pinnatum, $S$. filipendula var. laxum e s. vulgare var. foliosissimum, onde as plantas convivem em populações mistas com as variedades típicas correspondentes. Para nossa área, o significado destas variedades parece bastante questionável, mas têm sido consideradas na literatura recente (Taylor 1960, Earle 1969).

\section{Chave de identificação}

1 a - Ramos laterais primários ou de ordem mais elevada com projeções espiniformes....................... furcatum

b - Ramos laterais primários ou de ordem mais elevada

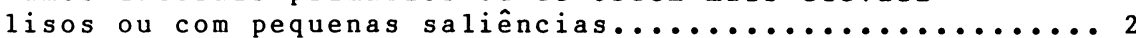

$2 a$ - Criptostomas pouco numerosos, distribuídos tenden do a formar uma fileira de cada lado da nervura ou muito escassos; folhas com bordo 1 iso, irregu-

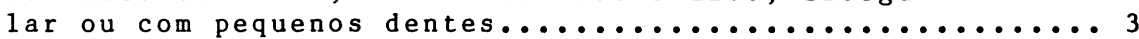

b - Criptostomas numerosos, irregularmente distribuídos na superfície da folha, se menos numerosos e tendendo a formar uma fileira de cada lado da ner vura, então as folhas possuem bordo tipicamente serreado.................................... 7

$3 a$ - Folhas muito longas e estreitas, quase 1 ineares, $\operatorname{com} 3-(4-6)-8 \mathrm{~cm}$ de comprimento e $(1-2)-3 \mathrm{~mm}$ de largura..................................... 4

b - Folhas mais curtas e usualmente mais 1argas............

4 a - Com alta frequência de folhas ramificadas.... S. ramifolium

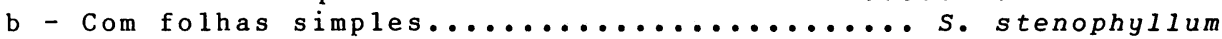


5 a - Plantas añ̃s, não ultrapassando $10 \mathrm{~cm}$ de compri mento, flutuadores nunca presentes, crescendo em costões extremamente batidos ........ s. cymossum var. nanum

b - Plantas maiores, flutuadores presentes ou não; crescem em costões mais protegidos..................6

$6 a$ - Folhas lanceoladas, com 2 - (3-5) - $7 \mathrm{~cm}$ de com primeiro e $3-(4-5)-8 \mathrm{~mm}$ largura; receptáculos em grupos com ramificação frouxa.... S. cymosum var. cymoum

b - Folhas oblanceoladas, menores, com $1,5-(2-3)-$ $5 \mathrm{~cm}$ de comprimento e 1 - $(2,5)-3 \mathrm{~cm}$ de 1 argura, receptáculos em racemos, com as ramificações

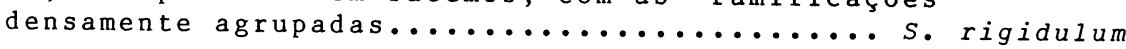

7 a Folhas 6-10 vezes mais longas que largas e distan ciadas umas das outras; plantas em geral muito grandes com $(40-50)-60 \mathrm{~cm}$ de comprimento...........8

b - Folhas 4-6 vezes mais longas que largas dispostas densamente ao longo dos eixos cilíndricos; plan tas menores................................... 11

$8 a-C o m$ alta freqüência de folhas ramificadas.......

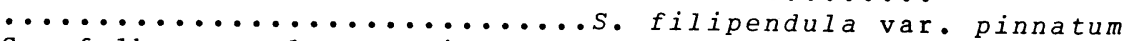

b - Com folhas geralmente simples.....................

9 a - Folhas com bordo 1 iso ou possuindo pequenos den -

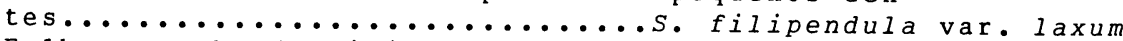

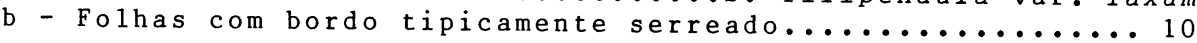

$10 a$ - Criptostomas pouco numerosos, às vezes formando uma fileira de cada lado da nervura das folhas; ramos laterais primários e folhas muito delicadas

b- triptosos, irregularmente disna superficie das folhas; 1 aterais pri-

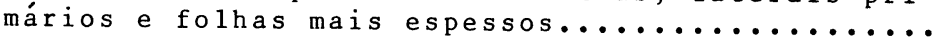
......................... filipendula var. filipendula

$11 \mathrm{a}-$ Folhas com $3-(7-8)-11 \mathrm{~mm}$ de 1 argura.........

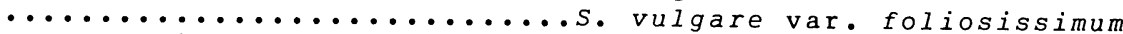

b - Folhas mais estreitas, com $(2-5)-7 \mathrm{~mm}$ de largura..... 12

$12 \mathrm{a}$ - Plantas añas, não ultrapassando $10 \mathrm{~cm}$ de comprimento; flutuadores nunca presentes, crescendo em

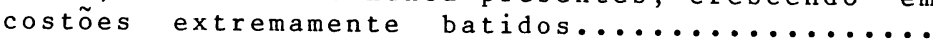

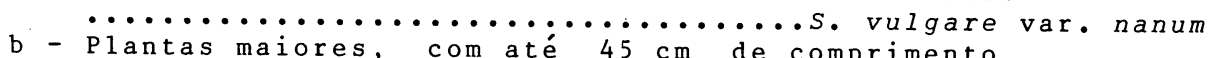
Plantas maiores, com até $45 \mathrm{~cm}$ de comprimento, flutuadores presentes ou não, crescendo em cos tões mais protegidos.................. vulgare var. vulgare

\section{Caracterização} 1. Sargassum cymosum C. Agardh var. cymosum Sp. Algar., p. 20.
1820 . 
Sargassum integrifolium Kg. Kuetzing 1849, P. 610; 1861, p. 5, t. 14 I.; Martens 1870 , p. 304.

Sargassum cymosum var. integrifolium (Kg.) Grunow. Grunow 1916, p. 142 .

Sargassum esperi Ag. Martius et al. 1833. p. 48; Kuetzing 1849, p. 612 ; Moebius 1889 , p. 324 .

Sargassum cymosum var. esperi (Sieber) Grunow. Grunow 1916 p. 142 .

Sargassum cheirifolium Kg. Moebius 1889, p. 324 .

Bibliografia básica: Dunal 1833, p. 450; St. Hilaire 1833, p. 447; Montagne 1839, p. 44; Kuetzing 1849, p. $614 ; 1861$, p. 8 t. 27 I; Martens 1870 , P. 304 ; 1871 , P. 146; Zeller 1876, p. 430; Piccone 1886, p. 284; Moebius 1889, P. 324. 1890, p. 1076; De Toni 1895, p. 87; Grunow 1916, p. 137; Luetzelburg 1923, p. 230; Howe 1928 , p. 189 ; Taylor $1930 \mathrm{a}$, P. $631 ; 1930 \mathrm{~b}$, p. $635 ; 1931$, p. 297; Rawitscher 1944, p. 15; Mattos 1952, P. 254; Joly 1957, P. $87, \mathrm{pr}$. IV, fig. 2, 2a, pr.V. fig. 5, 5a; Taylor 1960, p. 278, p1. 38, fig. 4; Nonato e Péres 1961, p. 265; Costa 1962, p. 200; Joly 1965, p. 96, pr. XI, XIII, fig. 116, 191-194; Ferreira e Pinheiro 1966, p. 62; Earle 1969, p. 216; Braga 1970, p. 25; Ugadim 1973 , p. 56; Bertossi e Ganesan 1973, p. 19, Lam. VIII, fig. 29-31; ? Baptista 1974, p. 80; pr. XVI, fig. 45-47; 01iveira Fi1ho e Mayal 1976, p. 306; 01iveira Fe 1977, p. 223.

Figs. 6, 27, 48-50,53, 54, 67

Plantas marrom-escuras quando vivas, enegrecendo ao secar; quando férteis medem $15-(25-30)-50 \mathrm{~cm}$ de altura. Apressório com até $3 \mathrm{~cm}$ de diâmetro, de onde parte grande número de ramos principais curtos, em cujo ápice diferenciam-se ramos laterais primários. Estes são longos, cilíndricos, lisos e providos de folhas e ramificações de primeira ordem. Folhas plano-lanceoladas, simples, raramente ramificadas, inseridas espiraladamente nos ramos cilíndricos, com os quais formam um ângulo geralmente agudo. Medem $2-(3-5)-7 \mathrm{~cm}$ de comprimento e $3-(4-5)-8 \mathrm{~mm}$ de largura; possuem margem lisa, irregular ou com pequenos dentes; nervura central evidente. Criptostomas pouco numerosos, dispostos em uma fileira de cada lado da nervura; ocorrem também nos ramos cilindricos e neste caso são alongados. Flutuadores pouco numerosos, próximos à porção terminal dos ramos, ou ausentes; são elípticos e apiculados quando jovens, e esféricos, não apiculados quando mais velhos, com até $5 \mathrm{~mm}$ de diâmetro; pedículo cilíndrico com 5 a $9 \mathrm{~mm}$ de comprimento. Plantas dióicas ou mais raramente monóicas; oogônios e anterídios localizados em conceptáculos separados. Receptáculos produzidos inicialmente na axila de folhas, posteriormente decíduas, em grupos com ramificação frouxa, dicotômica, podendo apresentar em sua porção basal um eixo central pouco diferenciado; receptáculos masculinos lisos e finos, com até $1,0 \mathrm{~cm}$ de comprimento; os femininos tuberculados, mais grossos, com até $0,7 \mathrm{~cm}$; os hermafroditas, semelhantes aos femininos, são mais densamente ramificados. 

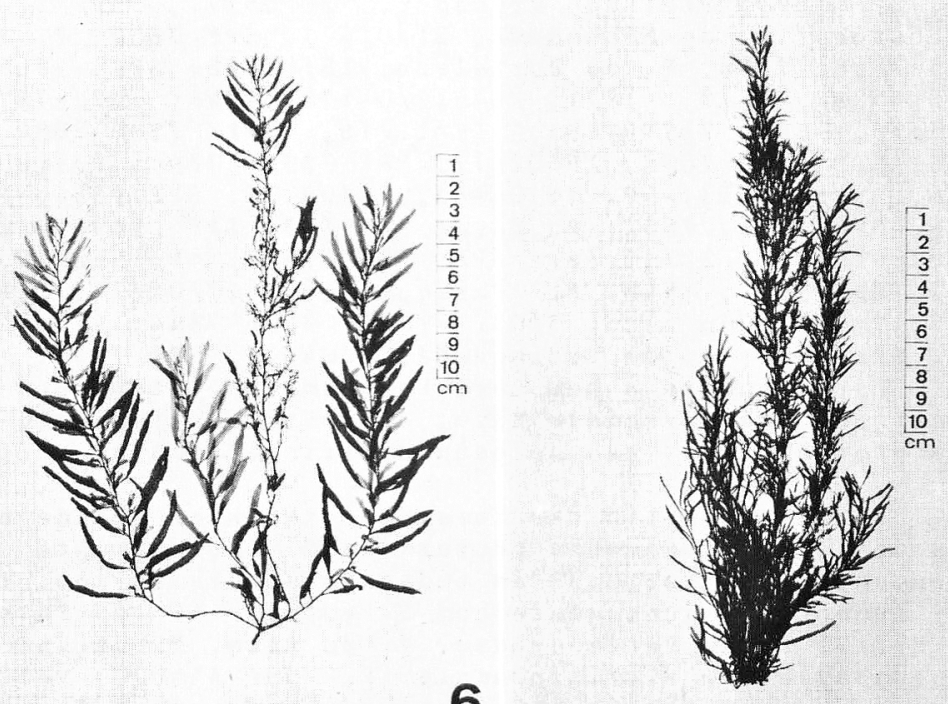

6
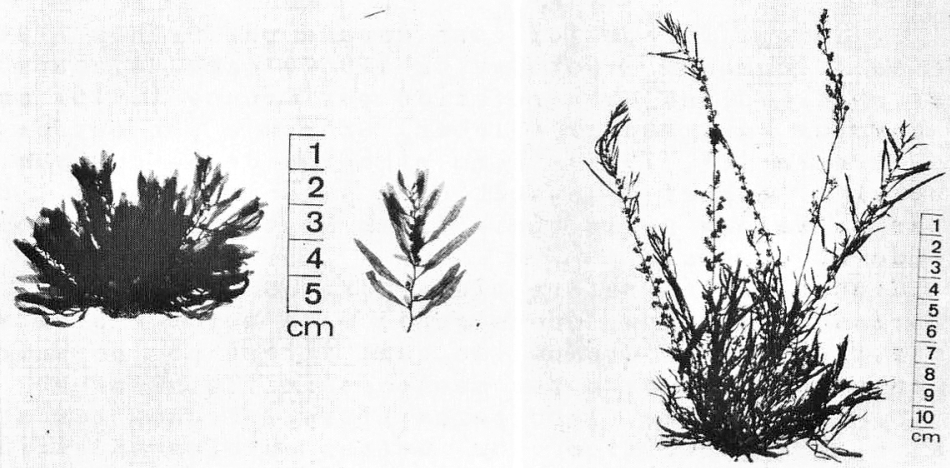

8

Figs. 6-9 - Aspecto geral das plantas.: 6 - S. cymosum var. cymosum, 7,9 - S. rigidulum. 8 - $S$. cymosum var. nanum, note um ramo fértil destacado.

Figs, 6-9 - Habit.: 6 - S. cymosum var. cymosum, 7,9 - S. rigidulum, 8 - S. cymosum var. nanum, note a fertile primary lateral on the right. 
Material examinado: Itanhaém, P. de Peruíbe (Cibrate1), 24/10/65, SPF 802. São Vicente, P. Paranapoan, 9/03/77, SPF 7825; I. Porchat, 1/05/50, SPF 1904. São Sebastião, P. de São Francisco, 9/07/63, SPF 1895; Pta.do Arpoador, 20/05/77, SPF 7859-7865, 8016. Ubatuba: P. de Maranduba, 21/02/77, SPF 7850; P. do Pulso, SPF 7855-7858,7866; P. da Fortaleza, 18/02/76, SPF 7868, 7869, $14 / 03 / 76$, SPF 7870, 7871, 14-17/04/76, SPF 7872-7876, 8105, 29-30/05/76, SPF 7877-7885, 19/11/76, SPF 7886-7889, 7895, $17 / 12 / 76$, SPF 7890-7892, 15/02/77, SPF 7893, 7894; Prainha Brava, 24/09/76, SPF 7853; P. do Costa, 24/09/76, SPF 7854; P. Brava, $24 / 09 / 76$, SPF 7851, 7852; P. Dura, 9/01/63, SPF 1896, 24/09/76, SPF 7826-7828, 22/10/76, SPF 7829-7833; P. Pereque-Mirim, $17 / 02 / 77$, SPF 7847, 7848; P. Pereque-Açú, 17/02/77, SPF 7845, 7846,7849 ; P. do A1to, 5/05/77, SPF 7836-7844; P. da Fazenda, $6 / 04 / 77$, SPF 7834; P. de Picinguaba, 6/04/77, SPF 7835 .

Esta espécie é bem caracterizada na literatura através de descriçóes da variedade tipo, tendo sido referida e descrita por numerosos autores; não apresenta dificuldades em ser reconhecida.

plantas bem típicas foram coletadas em grande número de estaçóes desde moderadamente protegidas a moderadamente batidas; foram encontradas férteis em todas as épocas do ano. Em locais onde foi encontrada juntamente com $S$. vulgare (P. do Pulso, P. do Perequê-Mirim, P. do Perequê-Assú, P. do Alto, P. da Fazenda e P. de Picinguaba) e com $S$. filipendula ( $P$. do Alto), verificou-se espécimens com caracteristicas intermediárias entre as duas espécies. Estes espécimens são de difícil tratamento taxonómico. Na Praia do Alto, por exemplo, além de espécimens típicos de $S$. cymosum, S. vulgare, S. filipendula e S. filipendula var. montagnei, observou-se outros que se assemelhavam à figuras dadas por Kuetzing (1861) para S. integrifolium Kuetz. e S. cheirifolium Kuetz •

S. integrifolium foi considerado por Grunow (1916) como variedade de $S$. cymosum e por Taylor (1960) como sinônimo deste último. S. cheirifolium está referido por Grunow (1916) como forma de $S$. cymosum var. esperi (Sieber) Grunow e por outros (Taylor 1960 e Oliveira Fe 1977) como sinônimo de S. cymosum. Taylor (1960) inclui S. esperi C. Agardh como. sinônimo de S. cymosum. Foram estas as razóes pelas quais foram mantidos esses nomes como sinônimos de $S$. cymosum.

Grunow (1916) refere ainda para o Brasil $S$. cymosum var. scabriuscula Grunow, que segundo este autor é próximo de $S$. cymosum var. lendigerum Grunow, do qual difere por possuir ramos moderadamente muriculados e por não possuir flutuadores.

S. cymosum var. lendigerum (Turn.) Grunow tem sido referido a nível específico por outros autores (Kuetzing 1861, Chapman 1963) e de acordo com Boergesen (1913, cf. Chapman 1963) está relacionado a $S$. vulgare, do qual pode ser variedade.

Estes fatos e a ausência de flutuadores em $S$. cymosum var. scabriuscula, sugerem que esta variedade possa tratar-se de

Figs. 10-13 - Aspecto geral das plantas.: 10-12 - s. stenophyllum, 13 - $s$. ramifolium.

Figs. 10-13 - Habit.: 10-12 - S. stenophyllum, 13 - S. ramifolium. 

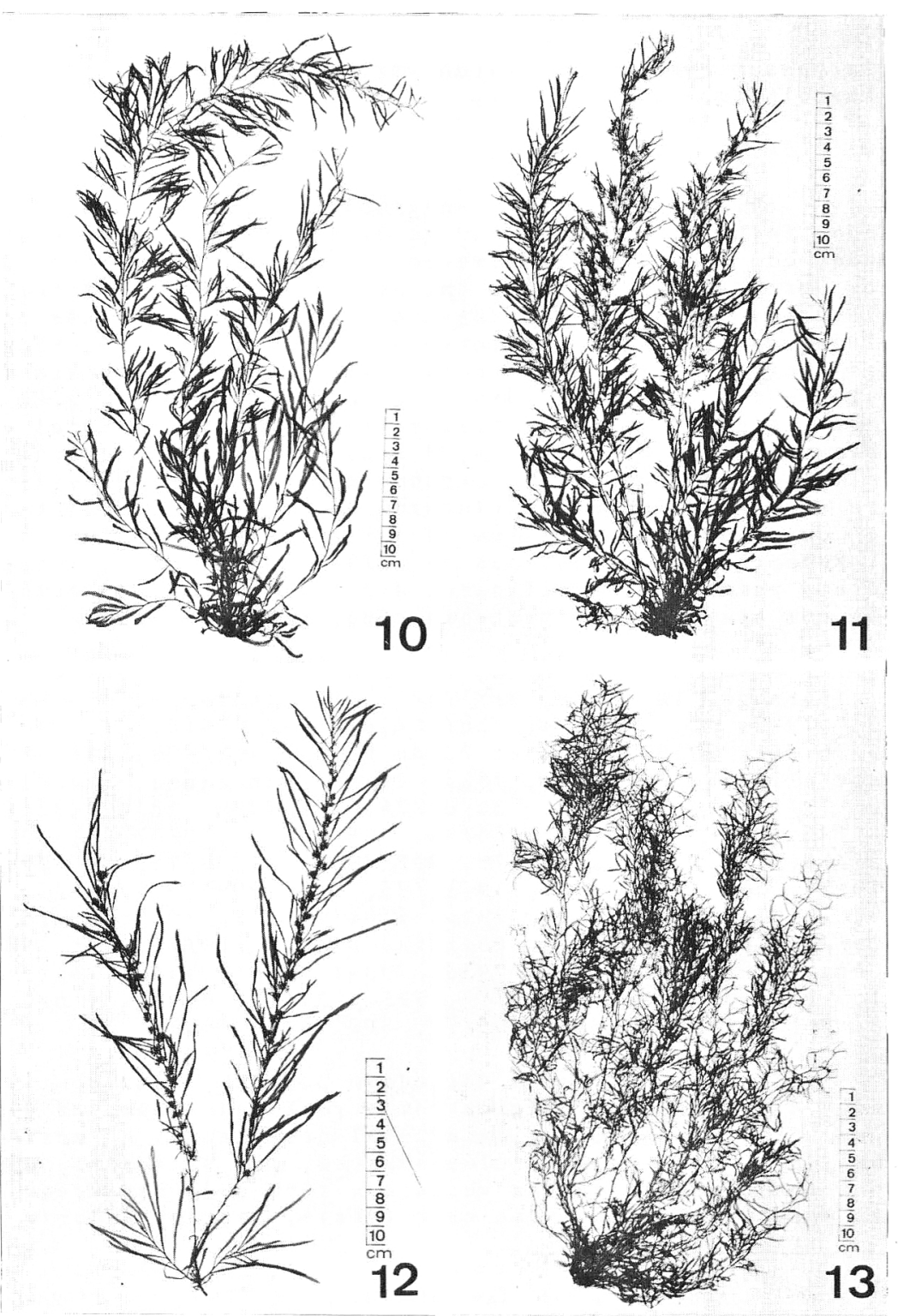
a lguma forma añ̃ de $S$. furcatum, $S$. vulgare ou ainda alguma forma intermediária, razão pela qual julgou-se mais adequado não considerar este binômio.

2. Sargassum cymosum C. Agardh var. nanun Paula \& 01iveira Fo. Phycologia, p. 145. 1982 .

Figs. 8,64

Plantas marrom, enegrecidas quando secas, medindo, quando férteis, (3-5) - $10 \mathrm{~cm}$ de altura. Apressório disciforme grande, com até $5 \mathrm{~cm}$ de diâmetro de onde parte grande número de ramos principais, com 1-3 cm, no ápice dos quais diferenciam-se os laterais primários, curtos, não ramificados. Folhas plano-1anceoladas simples, ou mais raramente ramificadas, inseridas espiraladamente nos ramos laterais primários, com os quais formam um ângulo agudo. Medem 2-(3-4) - $8 \mathrm{~cm}$ de comprimento e (2-4) - 6 $\mathrm{mm}$ de largura; possuem margem 1 isa e nervura central evidente. Criptostomas pouco numerosos, dispostos em duas fileiras, uma de cada lado da nervura, ocorrendo também nos eixos cilíndricos e neste caso são alongados. Flutuadores ausentes. Plantas monóicas, oogônios e anterídios localizados em conceptáculos separados. Receptáculos produzidos na axila das folhas, diretamente dos laterais primários, ramificados dicotomicamente, densamente agrupados com até $0,5 \mathrm{~cm}$ e protegidos por pequenas folhas.

Material examinado: Guarujá, $16 / 12 / 40$, SP 57988; Entre a P. do PC e P. I poranga, $10 / 09 / 76$, SPF 7921; P. Iporanga, 10/09/76, SPF 7919 , 7920; P. Branca, 28/10/76, SPF 7918; P. do Camburí, 9/09/76, SPF 7935. Ubatuba: P. do Pulso, 4/12/76, SPF 7922; P. do Bonete 4/12/76, SPF 7923, 7925; P. da Fortaleza, 24/05/75, SPF $6540,19 / 10 / 75$, SPF 6531, 31/01/76, SPF 7899, 18/02/76, SPF 7900, $30 / 05 / 76$, SPF 7926, 26/06/76, SPF 7901,13/07/76, SPF 7902, $14 / 07 / 76$, SPF 7903, 12/08/76, SPF 7904, 23/09/76, SPF 7905, 7906, $23 / 10 / 76$, SPF 7907, 7908, 19/11/76, SPF 7909-7912, 16/12/76, SPF $7913,16 / 02 / 77$, SPF 7914, 7916, 7/04/78, SPF 7915; Prainha Brava, 24/09/76, SPF 7932; P. Domingas Dias $22 / 10 / 76$, SPF 7927; P. da Sununga, 12-13/07/76, SPF 7933, 7934; Saco Grande, 16/12/76, SPF 7931 ; Perequê-Açu, $17 / 02 / 77$, SPF 7930; P. do Alto, 5/05/77, SPF 7928 ; P. de Itamambuca, 5/05/77, SPF 7917, 7929.

As plantas desta variedade possuem, indiscutivelmente, grande afinidade morfológica com a variedade tipo. As diferenças que se verificam na morfologia geral das plantas e morfologia e sexualidade dos receptáculos sugerem, por si mesmas, diferenças genotípicas. Populações da variedade tipo e da variedade anã, revelam acentuadas diferenças estruturais, encontrando-se férteis

Figs. 14-17 - Aspecto geral das plantas.: 14-15 - S. filipendula var. filipendula, note em 15 um ramo fértil e um jovem, destacados, $16-S$. filipendula var. laxum, 17 - S. filipendula var. montagnei.

Figs. 14-17 - Habit.: 14-15 - S. filipendula var. filipendula, note a young and a fertile denuded primary lateral destached in fig. $15 ; 16-\mathrm{S}$. filipendula var. laxum, 17 - S. filipendula var. montagnei. 

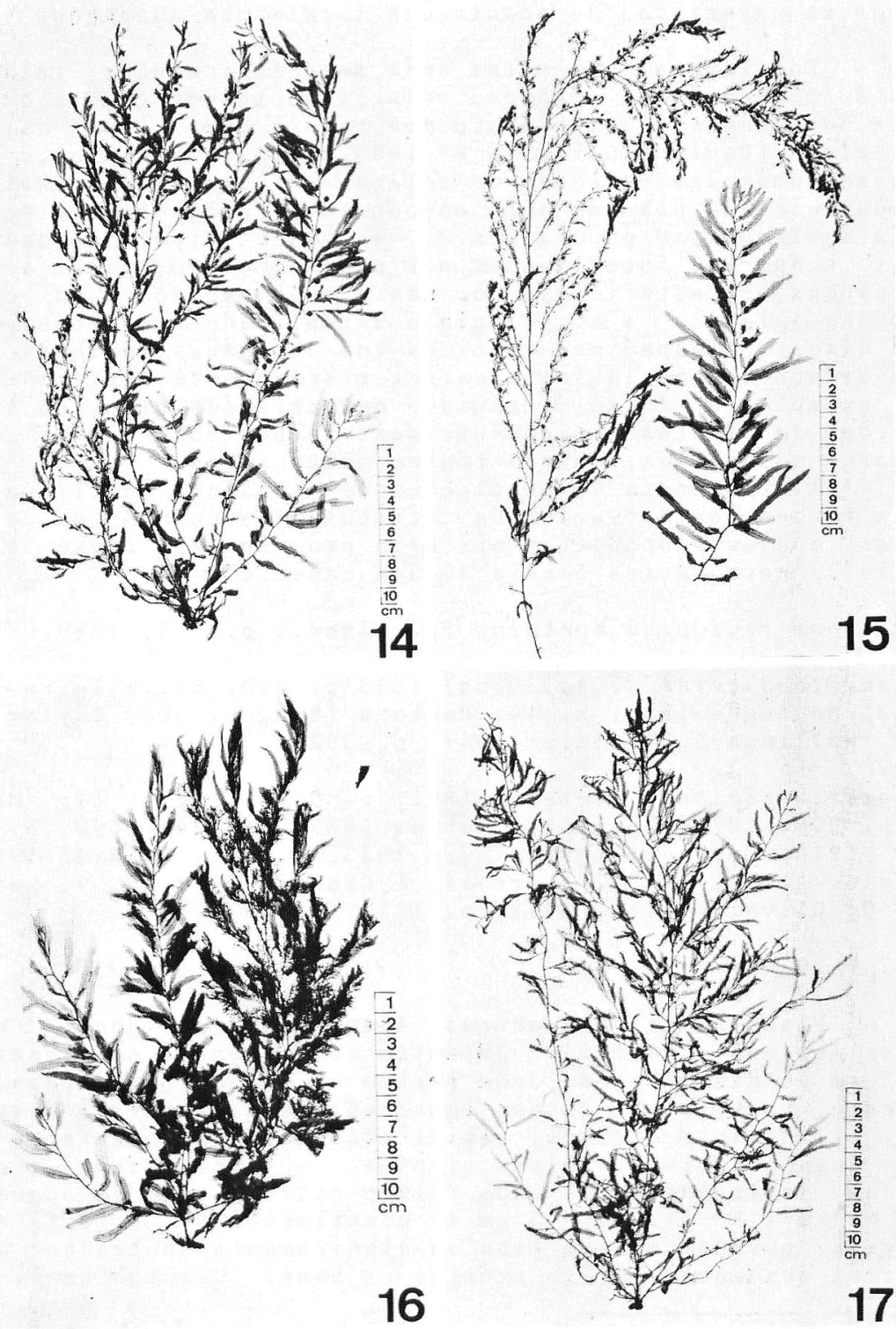
durante todo o ano (Paula \& 0liveira Fe 1980). Os resultados de experimentos de transplante (Paula \& 01 iveira Fa 1982) e de cultivo em laboratório (Paula 1984) reforçam a interpretação sobre a divergência genética de populações localmente adaptadas (ecótipos).

Populações de plantas anãs morfologicamente relacionadas à s. cymosum var. cymosum, relativamente homogêneas quanto à largura dos bancos e comprimento dos talos, como aquela da Ponta da Fortaleza (Paula \& Oliveira Fe 1980, 1982), ocorreram, ainda, em outras numerosas estações de coleta. Em algumas circunstâncias as populações de plantas anãs encontram-se geográfica e ecologicamente isoladas das populações da variedade tipo, enquanto em outras, acham-se interligadas por populações de transição muito heterogêneas, caracterizadas por uma grande variação no comprimento das plantas e morfologia e sexualidade nos receptáculos. Nestes casos, os espécimes monóicos com dimensões medianas podem ser considerados aqueles mais caracteristicamente intermediários. Esses exemplares foram incluidos na variedade tipo. Em algumas populações de plantas tipicamente anãs foram encontrados alguns exemplares masculinos, embora fossem muito raros.

A existência de populações de transição justifica a categoria taxonômica de variedade, atribuida às populaçóes de plantas anãs, que corresponde ao critério proposto por Davis \& Heywood (1973) para fácies locais de uma espécie.

3. Sargassum rigidulum Kuetzing Sp. Algar., p. 615, 1849 .

Sargassum lendigerum C. Ag. Duna 1833 p. 450; St. Hilaire 1833; p. 423; Montágne 1839, p. 44; Martens 1870, P. 304; Taylor 1931, p. 298; Williams \& Blonquist 1947, p. 392 .

Bibliografia básica - Kuetzing 1861, p. 9. T. 27, II; Martens 1870 , p. $304 ; 1871$, p. 146; Moebius 1889, p. 324; 1890, p. 1076; Grunow 1916, p. 46; Luetzelburg 1923, p. 231 ; Schmidt 1924, p. 90; Taylor 1960, p. 272; Bertossi \& Ganesan 1973, P. 9. Lam. II, fig. 6-8; 01iveira Filho 1977, p. 225 .

Figs . 7, 9, 29, 63

Plantas marrom- escuras, enegrecendo ao secar; quando férteis medem $5-(10-20)-38 \mathrm{~cm}$ de comprimento. Apressório com até $3,5 \mathrm{~cm}$ de diâmetro, de onde partem os ramos principais, extremamente reduzidos, quase imperceptíveis. Laterais primários longos, cilindricos e lisos, ramificados somente no maiores exemplares, quando férteis. Folhas simples, oblanceoladas, rígidas, inseridas espiraladamente nos eixos cilíndricos, emângulo bem agudo. Medem $1,5-(2,3)-5 \mathrm{~cm}$ de comprimento e $1-(2,5)-3 \mathrm{~mm}$ de largura, possuem margem 1 isa ou ligeiramente denteada e nervura central evidente, exceto próximo à base. Criptostomas pouco

Figs. 18-21 - Aspecto geral das plantas.: 18 - S. filipendula var. montagnei, 19 - S. filipendula var. pinnatum, 20-21 - S. vulgare var. vulgare.

Figs. 18-21 - Habit.: 18 - S. filipendula var. montagnei, 19 - S. filipendula var. pinnatum, $20-21$ - S. vulgare var. vulgare. 


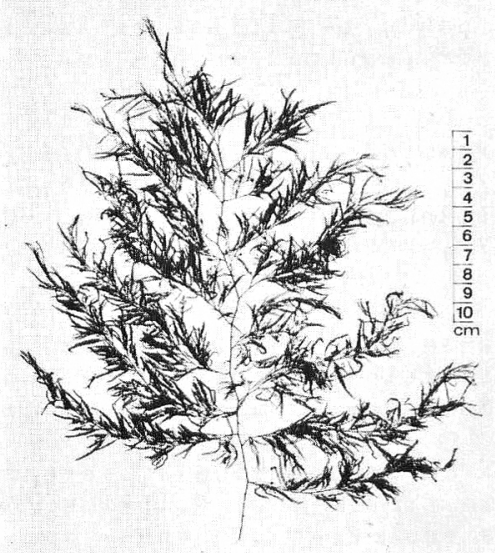

18



19

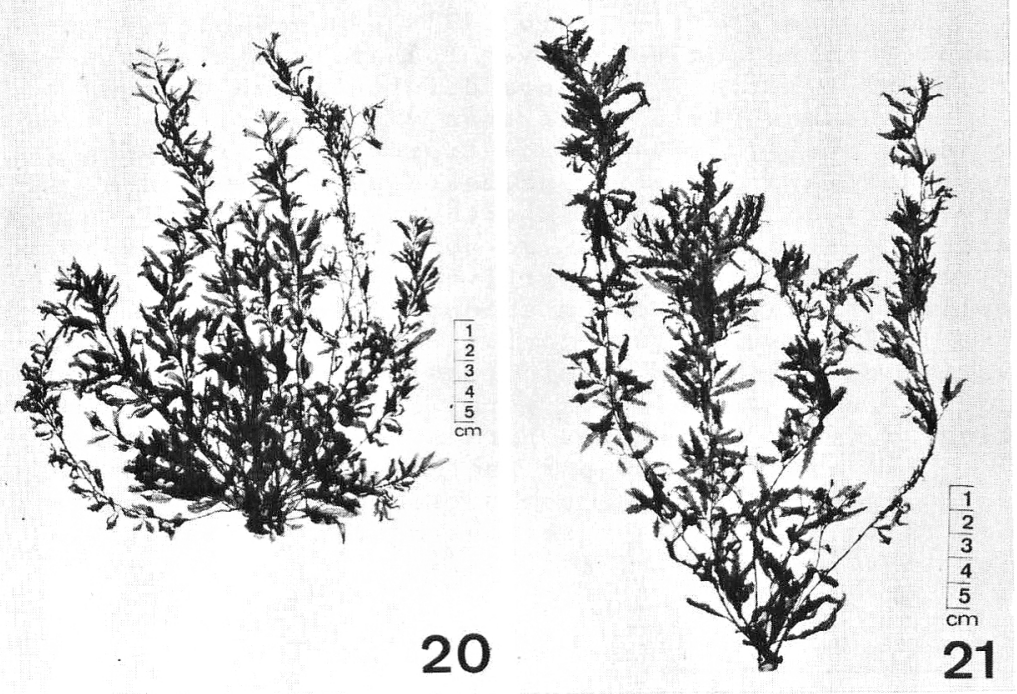


numerosos, dispostos em uma fileira de cada lado da nervura. Flutuadores ausentes ou muito raros, presentes apenas próximo ao ápice dos ramos maiores; esféricos, apiculados quando jovens, com cerca de $2 \mathrm{~mm}$ de diâmetro, pedículo cilíndrico com 2-3 mm de comprimento. Plantas monóicas; oogônios e anterídios localizados em conceptáculos separados. Receptàculos produzindos na axila das folhas, decíduas nos ramos velhos, em grupos racemosamente ramificados e densamente agrupados, sendo as últimas ramificaçós dicotômicas. O racemo, protegido por pequenas folhas, mede até 0,8 $\mathrm{cm}$.

Material examinado: Cananéia, Pta. de Itacuruçá, 20/01/57, SPF 775. Peruíbe: Prainha, 7/12/75, SPF 6534, 8/09/76, SPF 7554, $02 / 77$, SPF 7555, 7558, 8020. Itanhaém: P. Peruíbe (Cibratel) $1 / 01 / 51$, SPF 769, 1903, 07/76, SPF 7551, 7552, 28/03/77, SPF 7553.

Esta espécie assemelha-se à $S$. cymosum, mas pode ser facilmente reconhecida por suas folhas menores, oblanceoladas e por possuir receptáculos em racemos com ramificcações densamente agrupadas.

Foi encontrada somente em poucos locais, crescendo em costóes batidos a moderadamente protegidos. No primeiro caso as plantas dos níveis mais elevados são muito pequenas, com 3 a $4 \mathrm{~cm}$ e podem ser confundidas com S. cymosum var. nanum. Tornam-se progressivamente maiores com o aumento da profundidade. Nos locais moderadamente protegidos e poças, atingem maior comprimento. Foi encontrada fértil em diversas épocas do ano (fevereiro, março, junho, setembro e dezembro).

No verão (fevereiro 77) os exemplares coletados na Prainha (Peruíbe), apresentavam folhas irregulares a ligeiramente serrilhadas e muitas vezes com diferenciação de ramo no ápice.

Grunow (1916) cita três variedades para esta espécie, duas das quais, a variedade típica e s. rigidulum var. melneri Grunow, distinguidas principalmente pela sexualidade dos talos, refere para o Brasil. A importância da sexualidade dos talos na separação dessas variedades só poderá ser avaliada através de amostragens em áreas geográficas mais amplas, já que somente exemplares bissexuais foram encontrados.

E possível que plantas com pequenas dimensões ou anãs de várias espécies tenham sido incluidas sob essa denominação ( $S$. rigidulum) e de uma maneira geral confundidas entre outros com $S$. lendigerum (ver comentários para s. cymosum var. cymosum).

A prancha dada por Kuetzing (1861) para $S$, lendigerum possui alguma semelhança com $S$. rigidulum, mas também com $S$. Cymosum, razão pela qual preferimos manter a sinonímia dada por Taylor (1960) e 01 iveira Fo (1977).

Figs. 22-26 - Aspecto geral das plantas.: 22 - S. vulgare var. foliosissimum, 23-24 - S. vulgare var. nanum, 25-26 - S. furcatum.

Figs. 22-26 - Habit.: 22 - S. vulgare var. foliossissimum, 23-24 - S. vulgare var. nanum, 25-26 - S. furcatum. 


4. Sargassum stenophyllum (Mertens) Martius F1. Bras., p. 47, 1833 .

Sargassum cymosum var. stenophyllum (Mert.) Grunow. Piccone 1889 , P. 31; Moebius 1892, p. 22; Grunow 1916, p. 138 (v. stenophylla); Luetzelburg 1923, p. 231; Schmidt 1924, p. 90; Joly 1951, P. 133; 1957, p. 88, pr. IV, fig. 12, pr.XV, fig. 12, 12a; 1965 , p. 97 ; Braga 1970, p. 26; Ugadim 1973, p. 57; Baptista 1974, p. 82, pr.XVI, fig. 48 e 49; 01iveira Fo 1977, p. 244.

Sargassum cymosum var. stenophyllum f. apiculata Grunow. Grunow 1916 , p. 138 .

Bibliografia básica - Martius et al. 1833, p. 47; 1828-34, p. 8. t. V; Dunal 1833 , P. 450; St. Hilaire 1833, p. 447; Montagne 1839 , p. 44; De Toni 1895, P. 80; Grunow 1916, p. 31; Taylor 1960, p. 132 .

Figs . $10-12,28,51,52,55-57,68$

Plantas marrom-escuras, enegrecendo ao secar; quando férteis medem $15-(30-40)-60 \mathrm{~cm}$ de comprimento. Apressório com até $2,5 \mathrm{~cm}$ de diâmetro, de onde parte grande número de ramos principais, em cujo ápice diferenciam-se laterais primários muito finos e longos, pouco ramificados ou providos de ramificações de primeira ordem, longas e esparsas. Folhas simples, planas, quase lineares, em raros casos ramificadas, inseridas espiraladamente nos ramos cilíndricos, em um mesmo plano em determinadas porções, ou mesmo unilaterais, em ângulo agudo. São muito distanciadas umas das outras, exceto as terminais dos ramos velhos; muito longas e estreitas, medem $3-(5-6)$ - $8 \mathrm{~cm}$ de comprimento por 1 (2) - $3 \mathrm{~mm}$ de largura, possuem margem lisa e nervura central evidente. Criptostomas ausentes ou muito escassos. Flutuadores pouco numerosos, distribuem-se por toda a planta ou apenas próximo ao ápice, ou ainda ausentes; são elípticos e apiculados quando jovens e perfeitamente esféricos, não apiculados quando mais velhos, medem até $5 \mathrm{~mm}$ de diâmetro; pedículo cilíndrico com até 6 $\mathrm{mm}$ de comprimento. Plantas monóicas ou dióicas, oogonios e anterídios localizados em conceptáculos separados. Receptáculos produzidos inicialmente na axila das folhas, posteriormente deciduas, dos ramos laterais primários ou das ramificações destes, em grupos dicotomicamente ramificados, podendo apresentar um eixo central pouco diferenciado nas porções basais ou em racimos, com as últimas ramificaçóes dicotômicas. Receptáculos masculinos lisos e finos, com até $1,7 \mathrm{~cm}$ de comprimento; os femininos, tuberculados e mais grossos, medem até $0,5 \mathrm{~cm}$ e os hermafroditas medem até $0,8 \mathrm{~cm}$.

Figs. 27-30 - Porção superior de um ramo lateral primário.: 27 - S. cymosum var. cymosum, 28 - S. stenophyllum, 29 - S. rigidulum. 30 - S. filipendula var. filipendula.

Figs. 27-30 - Terminal part of a primary lateral.: 27 - S. cymosum var. cymosum, 28 - S. stenophyllum, 29 - S. rigidulum, 30 - S. filipendula var. filipendula. 


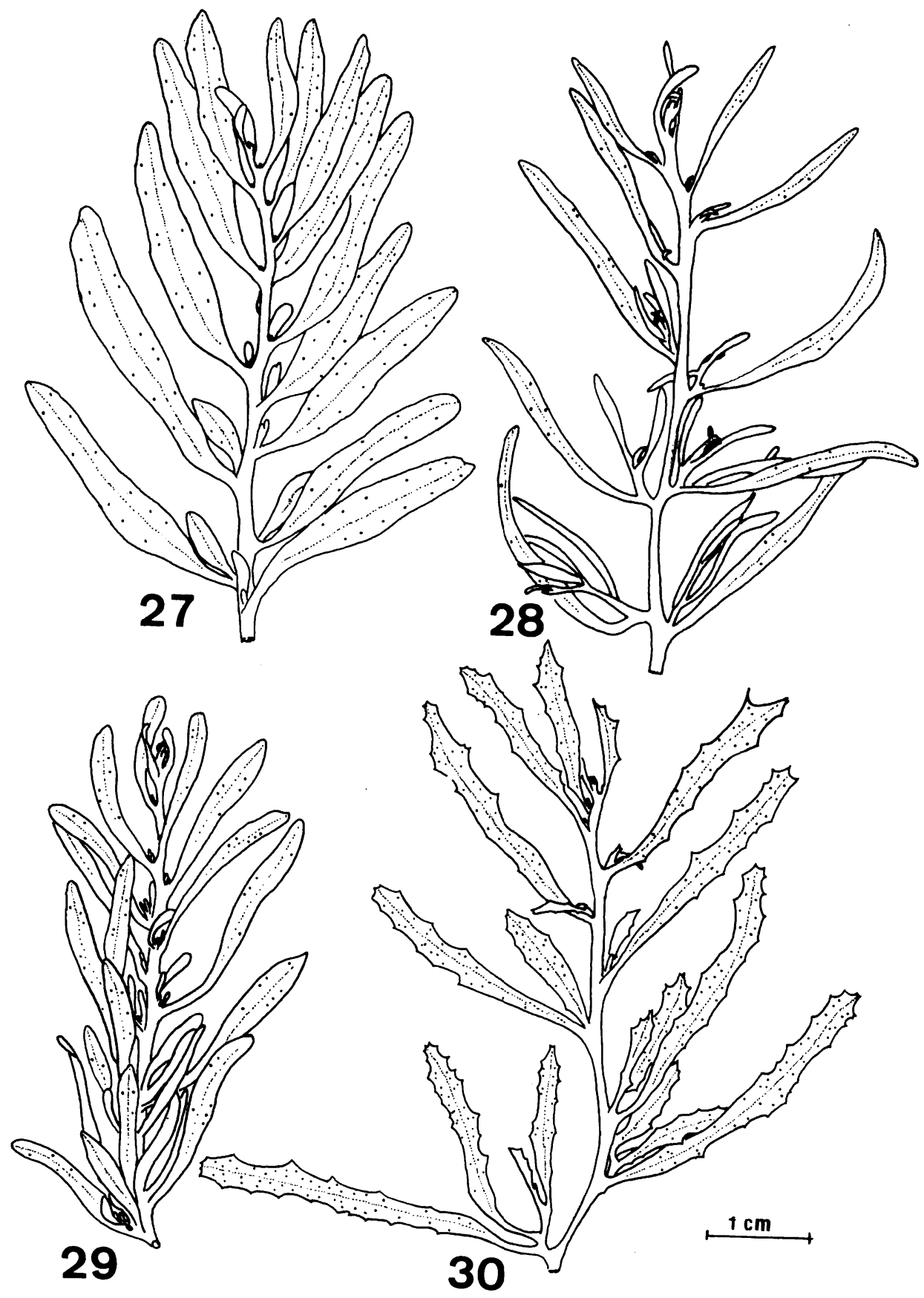


Material examinado: Cananéia, P. de Itacuruçá, 09/59, SPF 783 . Peruibe, Prainha 8/04/76, SPF 7797. Itanhaém, P. Peruíbe (Cibrate1) $24 / 10 / 65$, SPF $801,19 / 10 / 67$, SPF $812,13 / 07 / 65$, SPF 7798, 10/11/66, SPF 7799, 07/76, SPF 7800. São Vicente, I. Porchat, $27 / 07 / 53$, SPF 1902, 5356, 5683. São Sebastião P. São Francisco, 4/09/63, SPF $189413 / 12 / 77$, SPF 7801; P. da Cigarra, 13/12/77, SPF 7770; Pta. do Arpoador, 20/05/77, SPF 7802, 7820. Caraguatatuba, P. da Mococa, 18/07/76, SPF 7769. Ubatuba, P. do Pulso, 4/12/76, SPF 7766,7768; P. do Bonete, 4/12/76, SPF 7760, 7765; P. Brava e Prainha Brava (B. da Fortaleza) 22/09/76, SPF 7757, 7759 ; P. Dura, 24/09/76, SPF 7774, 7777, 22/10/76, SPF 7771, $7773,7778,7782$; P. Domingas Dias, 22/10/76, SPF 7783, 25/07/61, SP 96444; P. do Lázaro, 3/07/53, SPF 1901, 13/07/76, SPF 7784-7790; Perequê-Mirim - 21/01/77, SPF 7791; Perequê-Açú 9/09/50, SPF 1905; P. Prumirim-6/05/77, SPF 7792-7794; P. do Meio - 6/05/77, SPF 7796; P. de Picinguaba - 6/04/77, SPF 7795 .

Muitos autores recentes tratam este táxon como variedade de $S$. cymosum. Considerando-se, entretanto, no seu conjunto, o tratamento taxonômico e as dificuldades da delimitação das espécies em geral, e a facilidade relativa com a qual estas plantas podem ser reconhecidas, justifica-se a categoria de espécie proposta por Taylor (1976). Pode ser facilmente reconhecida por suas folhas longas, estreitas, quase lineares, com bordo liso e criptostomas escassos ou ausentes.

As plantas são muito flexíveis, características dos costões onde as ondas formam uma correnteza, sem impacto direto. Foram encontradas em um grande número de estações de coleta, férteis em todas as épocas do ano. Quando convive com outras espécies ( $S$. cymosum, $S$. vulgare, $S$. filipendula), cresce nos níveis mais inferiores, próximos da areia ou em poças.

Plantas anãs relacionadas a esta espécie foram verificadas na Ponta do Bonete, crescendo próximas ao limite superior de sua zona vertical de distribuição, nos costões muito batidos. Neste caso, entretanto, não ocorreu nenhuma descontinuidade populacional com relação às plantas maiores.

Grunow (1916) reconhece este táxon como variedade de $S$. cymosum e propõe ainda uma forma ( $S$. cymosum var. stenophyllum f. apiculata Grunow), a qual refere para o Brasil. Segundo este autor esta forma difere pela presença ou não de uma expansão foliar no ápice dos flutuadores. Segundo nossas observaçóes, entretanto, esta característica é muito variável, mesmo dentro de um único espécime, de maneira que essa distinção não nos parece justificada.

5. Sargassum ramifolium Kuetzing Phyc. Gener., p. 362. 1843

Sargassum cymosum var. ramifolia (Kuetz.) Grunow, Grunow 1916, p. 141 .

Figs. 31-33 - Porção superior de um ramo lateral primário.: 31 - 5 . ramifolium, 32 - S. vulgare var. vulgare. 33 - S. furcatum.

Figs. 31-33 - Terminal part of a primary lateral.: 31 - S. ramifolium, 32 S. vulgare var. vulgare. 33 - S. furcatum. 
Sargassum no Litoral de São Paulo

97
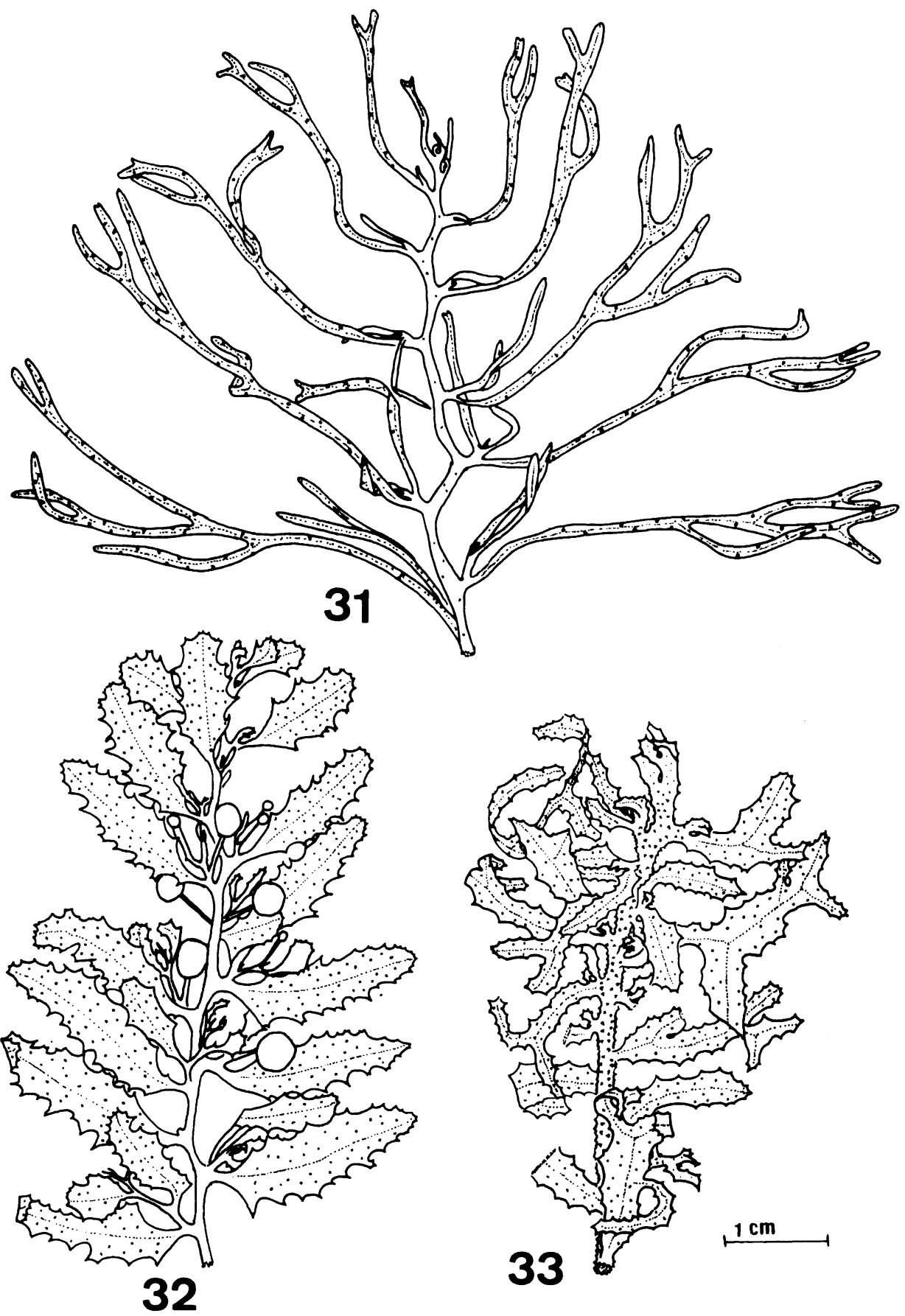
Bibliografia básica - Kuetzing 1849, p. 616;1861, p. 10, t. 32 I; Martens 1870 , p. 304; Zeller 1876, p. 430; Taylor 1960, p. 278; Bertosi e Ganesan 1973, p. 7, lam. I fig. 1-5; oliveira Fo 1977 , p. 334 (como referência duvidosa).

Figs. $13,31,46-47,60,71$

Plantas escuras quando vivas, enegrecendo ao secar; quando férteis medem 25 - (35-40) - 75 cm de comprimento. Apressório com até $1,5 \mathrm{~cm}$ de diâmetro de onde partem os ramos principais muito curtos. Laterais primários cilindricos, lisos ou com criptostomas ligeiramente salientes nas porções jovens, finos e longos e com grande número de ramos de primeira ordem. Folhas planas, simples, lineares ou mais tipicamente pinadas ou furcadas uma a cinco vezes, dispostas distica ou espiraladamente, em ângulo aberto em relação aos ramos cilíndricos. São geralmente distanciadas umas das outras, medem $3(4-5)-6 \mathrm{~cm}$ de comprimento por (1-2) - $3 \mathrm{~mm}$ de largura; possuem margem lisa ou irregular e nervura central evidente. Criptostomas escassos nas folhas inferiores e pouco numerosos, em uma fileira de cada lado de nervura nas superiores. Flutuadores ausentes ou pouco numerosos, próximos à porção terminal das plantas, esféricos, com 3-4 mm de diâmetro, produzidos na extremidade de pedículos cilíndricos com até $5 \mathrm{~mm}$ de comprimento. Plantas dióicas. Receptáculos em racimos, com as últimas ramificações dicotômicas; presentes na axila das folhas do ápice dos laterais primários ou mais comumente em ramificações deste. Receptáculos femininos tuberculados com até $0,7 \mathrm{~cm}$ de comprimento; os masculinos rugosos, mais finos, medem até $2 \mathrm{~cm}$.

Material examinado: Ubatuba, P. da Fortaleza - 24/05/75, SPF 6539 - $19 / 10 / 75$, SPF 6532, 6533 - 29/05/76, SPF 7523-30/05/76, SPF $7524,7525-26 / 06 / 76$, SPF $7526-7529$ - 12/08/76, SPF 7530-7533 $23 / 09 / 76$, SPF $7534-23 / 10 / 76$, SPF $7535-19 / 11 / 76, \quad$ SPF $7536-7550$.

Esta espécie assemelha-se à s. stenophyllum pelas dimensões das folhas e dos talos, mas pode ser distinguida pelas folhas furcadas e receptáculos mais longos e mais ramificados. As

Figs. 34-52 - Folhas.: 34-37 - S. furcatum, 34,36 - folhas de ramo adulto, 35,37 - folhas de ramo jovem, 38-39 - S. vulgare var. vulgare. 40 - s. vulgare var. foliosissimum. 41 - S. filipendula var. filipendula, 42 - S. filipendula var. pinnatum. 43,45 - S. filipendula var. montagnei. 44 - S. filipendula var. laxum. 46-47 - S. ramifolium, 46 - folhas de ramo adulto, 47 - folhas de ramo jovem, 48-50 - S. cymosum var. cymosum. 51-52 - S. stenophyllum.

Figs. 34-52 - Leaves.: 34-37 - S. furcatum, note leaves from mature branch in fig. 34 and 36 and leaves of a young branch in figs. 35 and $37,38-39$ - $\mathrm{s}$. vulgare var. vulgare, 40 - S. vulgare var. foliosissimum, 41 - S. filipendula var. filipendula, 42 - S. filipendula var. pinnatum. 43,45 - S. filipendula var. montagnei. 44 - S. filipendula var. laxum, 46-47 - S. ramifolium, note leaves of a mature branch in fig. 46 and leaves of a young branch in fig. 47, 48-50 - S. cymosum var. cymosum, 51-52 - S. stenophyllum. 

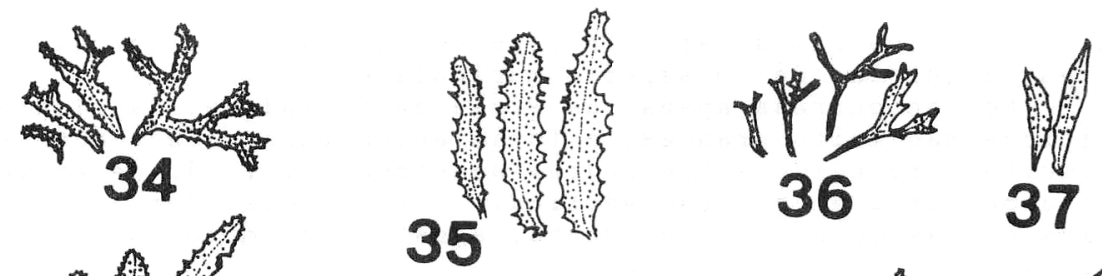

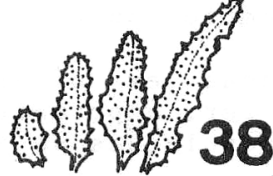
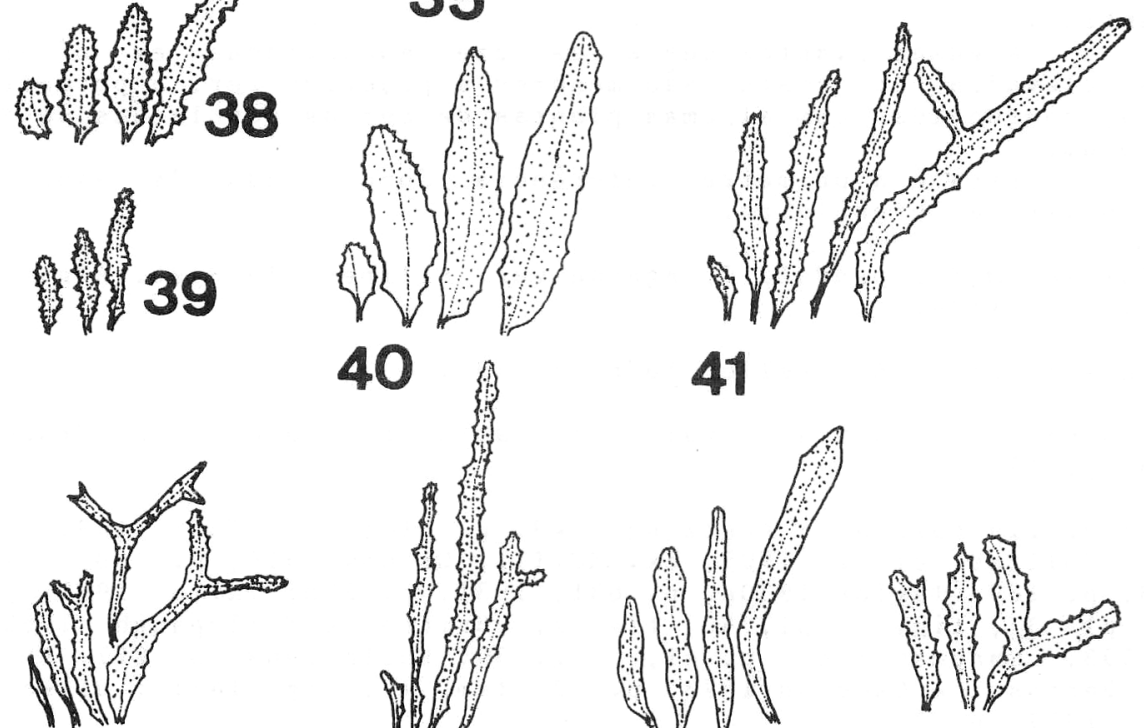

42
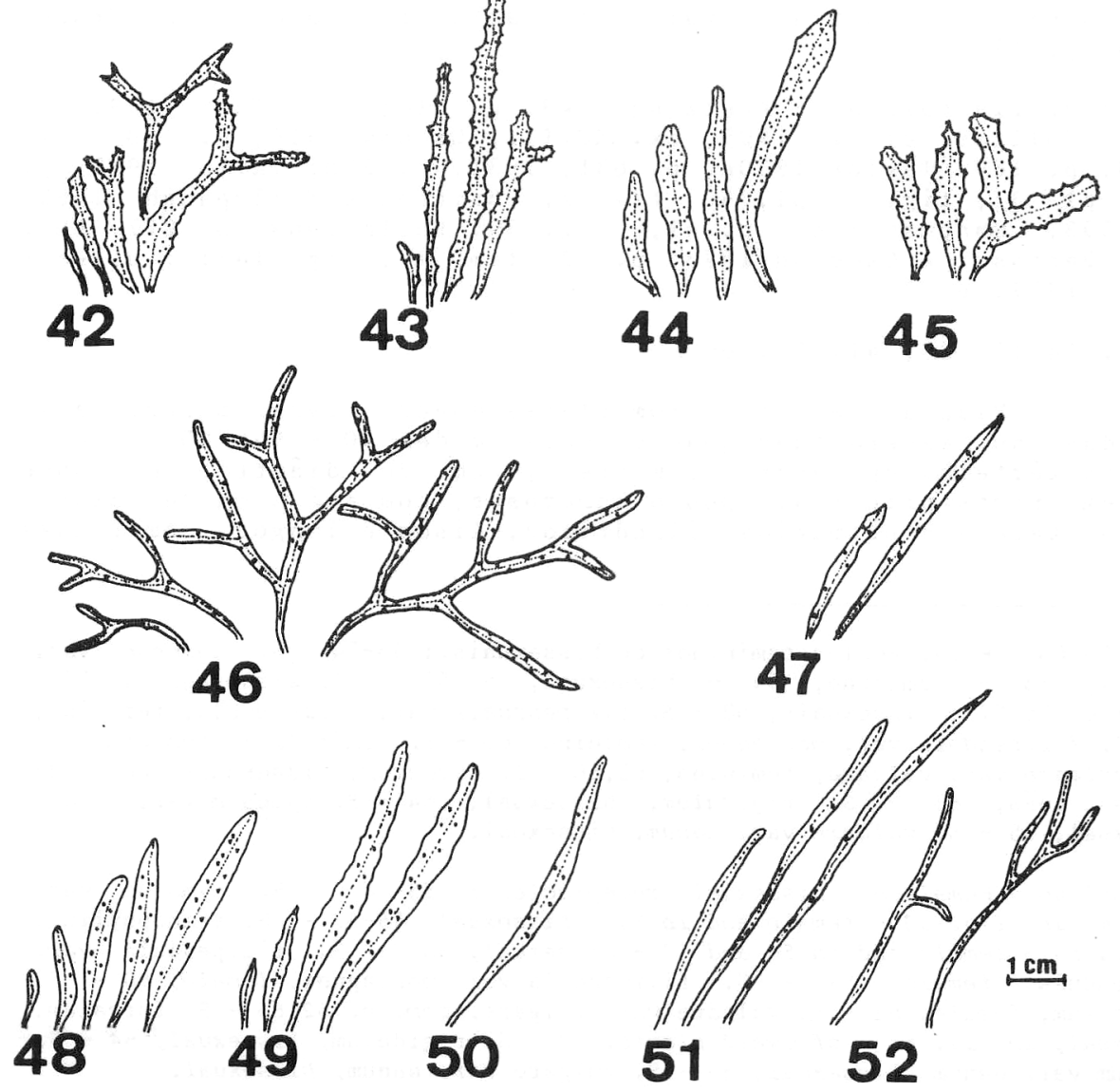
porções jovens dos ramos laterais possuem, às vezes, criptostomas salientes, o que lhe dá um aspecto muriculado.

Foi encontrada apenas na Praia da Fortaleza. As plantas mais típicas sa muito grandes, e foram encontradas crescendo em local muito protegido sobre pedras acentadas em fundo de areia, sempre submersas e em posição vertical. Foram coletadas férteis em várias épocas do ano (maio, junho, agosto, setembro, outubroe novembro).

Algumas plantas desta espécie encontradas em níveis mais elevados da costa sãomenores e poderiam ser, à primeira vista, confundidas com algumas plantas de certas populaçóes de $S$. furcatum.

Esta é a primeira referência documentada da espécie para o litoral brasileiro.

6. Sargassum filipendula C. Agardh var. Filipendula Syst. Algar., p. 300.1824 .

Sargassum affine Ag. Zeller 1876, p. 430 .

Sargassum filipendula var. contracta f. pardacenta. Grunow 1916, p. 170 .

Bibliografia básica - Kuetzing 1849, p. 614; De Toni 1895, p. 106; Collins et al. 1905, ex. XCVIII; Grunow 1916, P. 168; Howe 1928 , p. 189; Taylor 1930a, P. 631; 1931, P. 298; Taylor 1960, p. 270, pl. 37, fig. 3. pl. 40, fig. 2; Britton e Millspaugh 1962, p. 593; Chapman 1963, p. 41, fig. 39; Earle 1969, p. 217, fig. 117; Bertossi e Ganesan 1973, p. 12, lam. IV, fig. 14-16; 01iveira Fo 1977 , p. 224 .

Figs. $14-15,30,41,58,69$

Plantas de cor marrom-claras quando vivas, marrom amareladas ou esverdeadas quando secas; medem $30-(40-50)-60 \mathrm{~cm}$ quando férteis. Apressório com até $1,5 \mathrm{~cm}$ de diâmtro, de onde partem ramos principais pouco numerosos, com até $3 \mathrm{~cm}$ de comprimento. Laterais primários cilíndricos, lisos e longos, com folhas

Figs. 53-66 - Receptáculos femininos ou bissexuais.: 53-54 - S. cymosum var. cymosum, 53 - feminino, 54 - bissexual, 55-57 - S. stenophyllum, 55 feminino, 56-57 - bissexuais, 58 - S. filipenduala var. filipendula, feminino, 59 - S. filipendula var. montagnei, feminino. 60 - S. ramifolium, feminino, 61 - S. vulgare var. vulgare, feminino, 62,66 - S. furcatum, bissexuais, 66 - de plantas anãs, 63 - S. rigidulum, bissexual, 64 - S. cymosum var. nanum, bissexual, 65 - S. vulgare var. nanum, bissexual.

Figs. 53-66 - Female or bissexual receptacles.: 53-54 - S. cymosum var. cymosum in fig. 53 - female and in 54 - bissexual, 55-57 - S. stenophyllum, in fig. 55 - female and in 56 and 57 - bissexual, 58 - S. filipendula var. filipendula, female, 59 - $-\mathrm{S}$. filipendula var. montagnei, female, 60 - $\mathrm{S}$. ramifolium, female, 61 - S. vulgare var. vulgare, female. 62,66 - S. furcatum, bissexual, in fig. 66 - of dwarf plants, 63 - S. rigidulum, bissexual, 64 - S. cymosum var. nanum, bissexual, 65 - S. vulgare var. nanum, bissexual. 


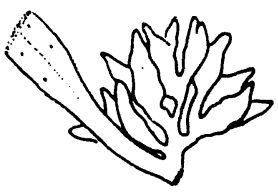

53

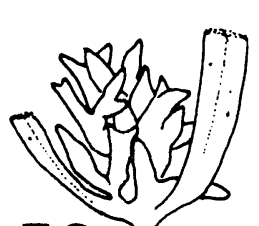

56
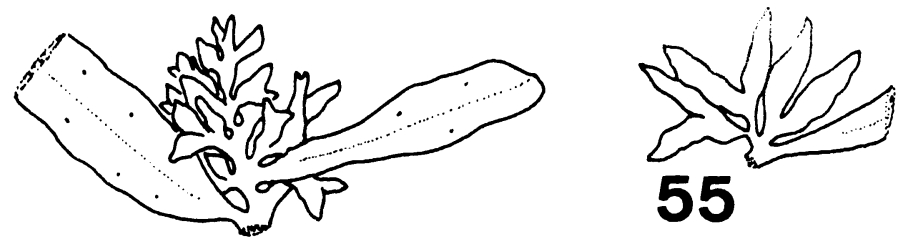

54

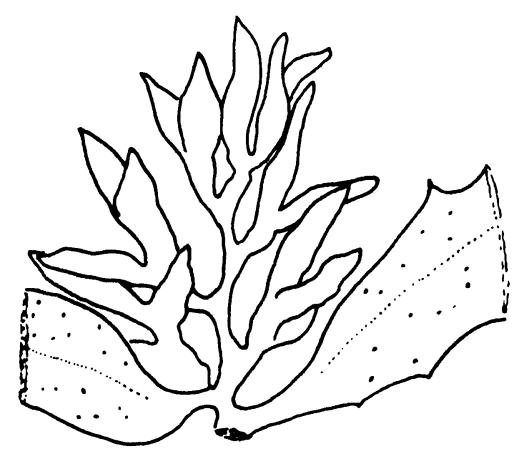

58

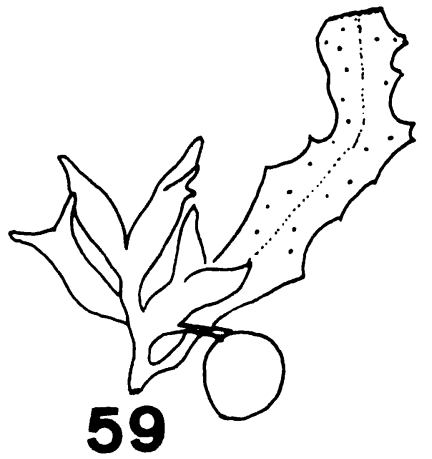

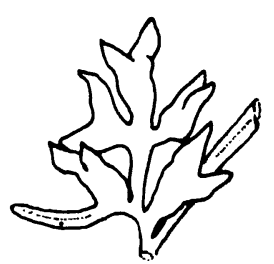

60
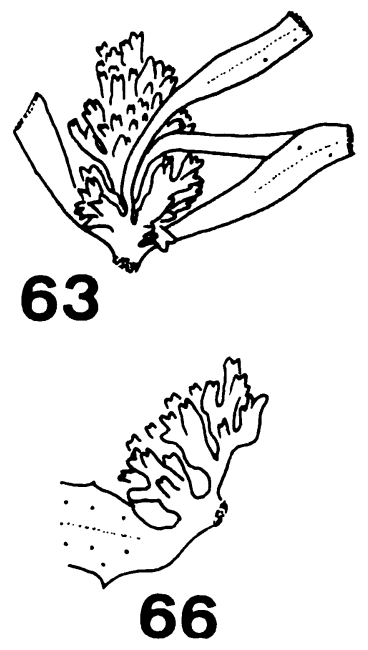
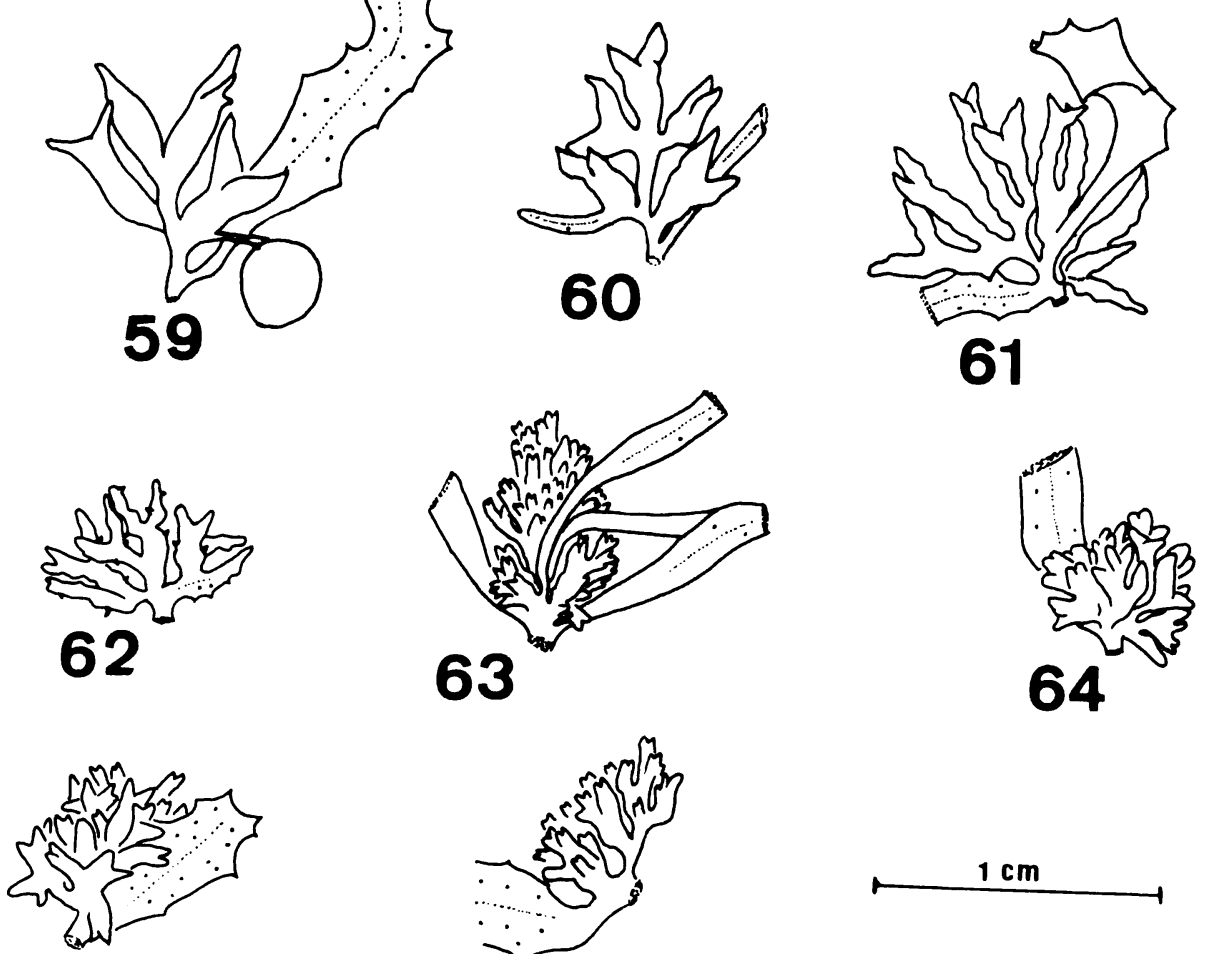

65

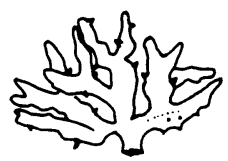

62 
e ramos de primeira ordem longos e dispostos em espiral frouxa. Folhas simples, planas, linear-lanceoladas, as mais inferiores podendo ser ramificadas uma vez; com base afilada lembrando um peciolo. Medem $3-(4-5)-8 \mathrm{~cm}$ de comprimento por $3-(4-5)-6$ mm de largura, com margem serreada e nervura central evidente. Criptostomas numerosos, irregularmente distribuidos na superficie da folha. Flutuadores numerosos, distribuidos por toda planta, quando presentes; são elípticos, com cerca de $3 \mathrm{~mm}$ de diâmetro, apiculados ou terminados por expansão foliar, pedículo com cerca de 3-4 mm de comprimento. Plantas dióicas, receptáculos em racimos, com as últimas ramificações dicotômicas, produzidos especialmente nas ramificaçós dos laterais primários; femininos tuberculados com até $1,3 \mathrm{~cm}$ e masculinos mais finos e mais ramificados com até $2,5 \mathrm{~cm}$.

Material examinado: Cananéia, I, do Bom Abrigo, 18/01/57, SPF 776. Ubatuba, P. do Lamberto (P. da Base), 11/07/61, SPF 1898, $24 / 07 / 61$, SP $96443,15 / 12 / 76$, SPF 7937, 7938; P. do Alto, $5 / 04 / 77$, SPF 7939,7945 .

A espécie foi coletada fértil em abril e dezembro, em locais extremamente protegidos ( $P$. do Lamberto e Saco da Ribeira), ou mais expostos ( $P$. do Alto). No primeiro caso crescem em pedras permanentemente submersas, em posição vertical, ficando, nas marés baixas, as porções terminais flutuando na superfície da água.

Na Praia do Lamberto e Saco da Ribeira, além da variedade tipo, foram coletados exemplares com caracteristicas que concordam, de uma maneira geral, com a descrição dada por Taylor (1960) e Earle (1969) para S. filipendula var.pinnatum e $S$. filipendula var. laxum. Na Praia do Alto a variedade tipo foi encontrada convivendo com S. filipendula var. montagnei, entre outras espécie do gênero. Um exame em áreas geográficas mais amplas seria necessário para avaliar a validade da categoria taxonômica de variedade atribuída nestes casos.

S. filipendula var. contracta f. pardacenta Grunow foi referida para o Brasil (Grunow 1916). Este autor, combase na figura dada por Kuetzing (1861), reconhece $S$. affine Ag. como sinônimo daquela forma. S. affine Ag. foi referida para o Brasil por Zeller (1876). A figura dada por Kuetzing (1861) para $S$. affine não dá margem a dúvidas de que se trata de $S$ filipendula, razão pela qual foram incluidos esses nomes como sinônimos.

ral de São Paulo.

Esta é a primeira referência da variedade para o 1ito-

Figs. 67-73 - Receptáculos masculinos. 67 - S. cymosum var. cymosum. var. cymosum. 68 - S. stenophyllum. 69 - S. filipendula var. filipendula. 70 - S. filipendula var. montagnei. 71 - S. ramifolium. 72 - S. vulgare var. vulgare. 73 - S. furcatum.

Figs. 67-73 - Male receptacles. 67 - S. cymosum var. cymosum. 68 - S. stenophyllum. 69 - S. filipendula var. filipendula. 70 - S. filipendula var. montagnei. 71 - S. ramifolium. 72 - S. vulgare var. vulgare. 73 - S. furcatum. 

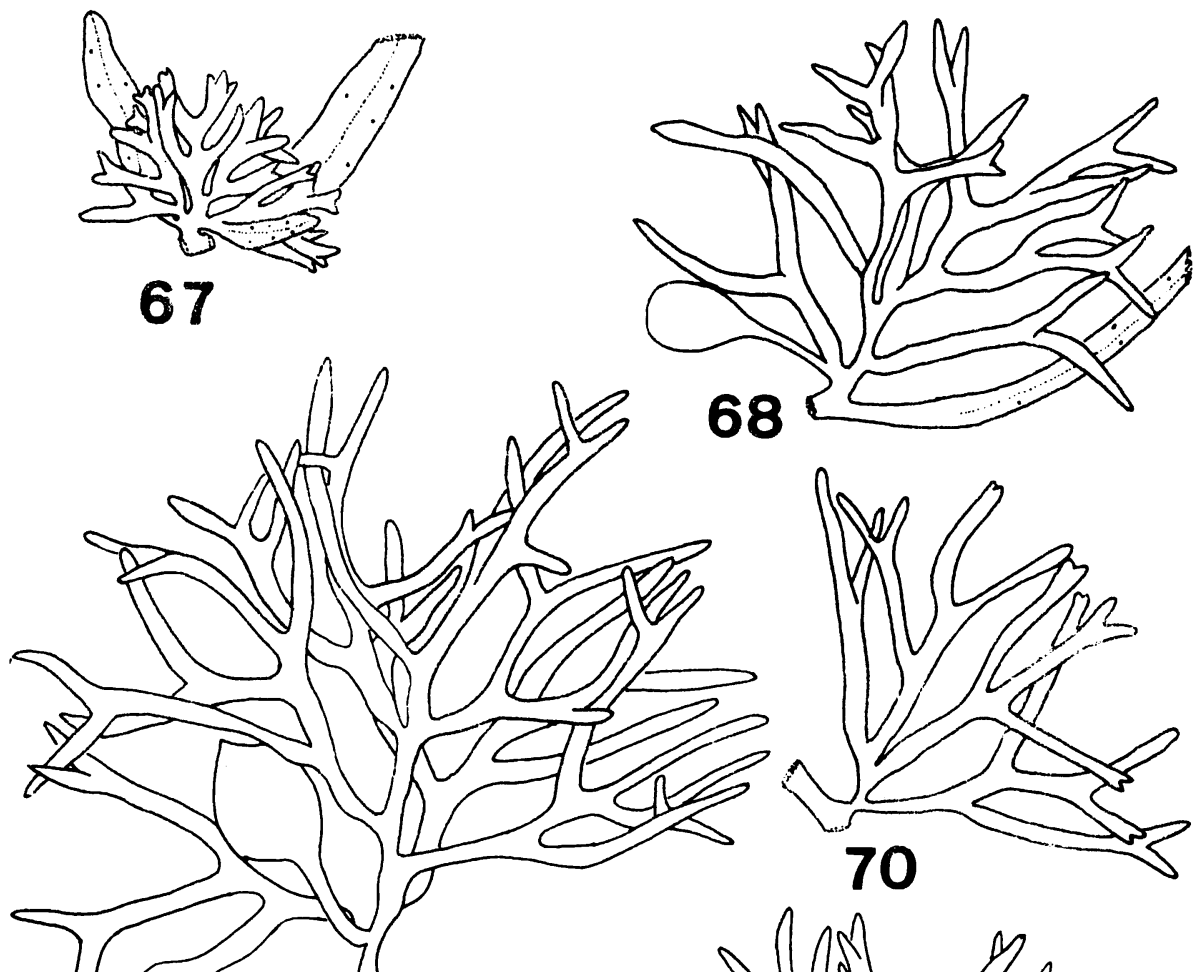

$\sqrt{6} 69$
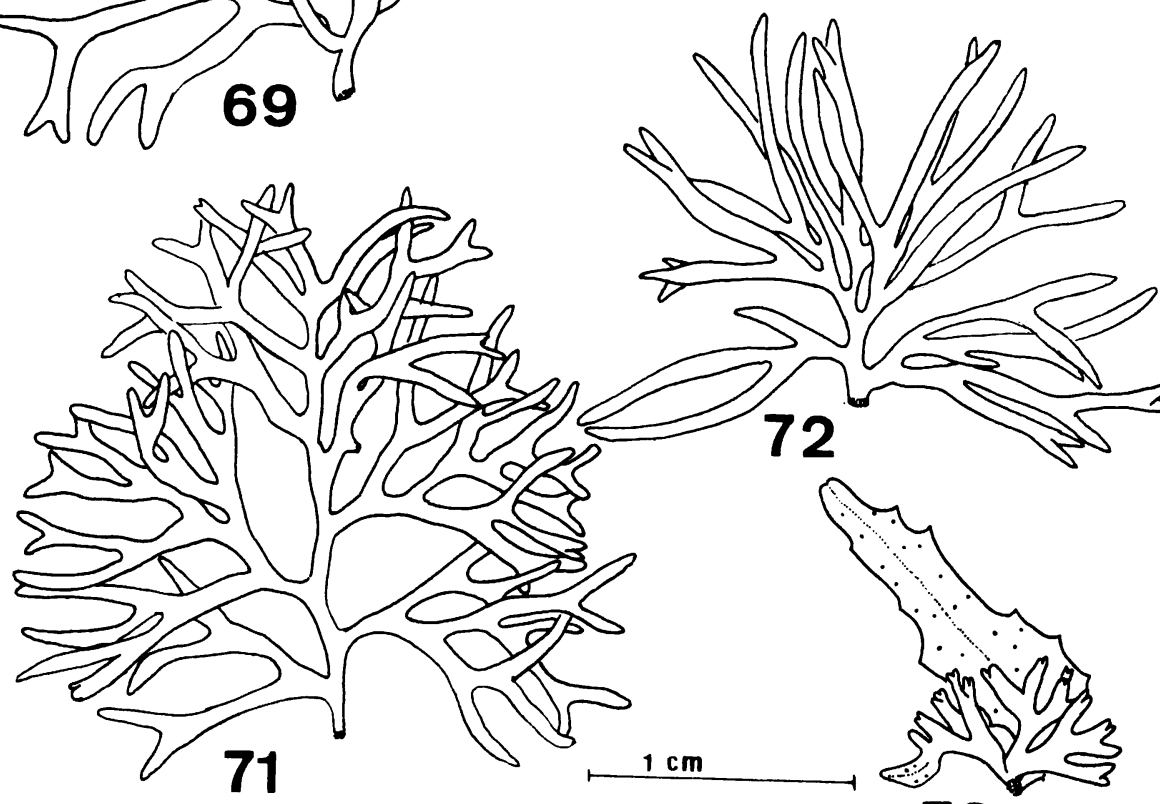
7. Sargassum filipendula C. Agardh var. montagnei (Bailey) Grunow Addit. Cog. Sarg., p. 171.1916.

Bibliografia básica - Taylor 1960, p. 271; Earie 1969, p. 220; Bertossi \& Ganesan 1973, p. 14, 1am. V., fig. 17-19.

Figs. $17-18,43,45,59,70$

Plantas marrom-claras quando vivas, esverdeadas ao secar; tão longas quanto a variedade típica, medindo $20-(40-50)$ - $60 \mathrm{~cm}$, quando férteis. Diferem da variedade típica por possuirem laterais primários muito finos; folhas com bordo serreado, muito delicadas e mais estreitas, com $(2-3)-7 \mathrm{~cm}$ de comprimento e $(2-3)-5 \mathrm{~mm}$ de largura. As folhas são comumente dispostas num único plano, alternadamente opostas ou unilaterais, e mais raramente em espiral em torno dos eixos cilíndricos. Criptostomas pouco numerosos e irregularmente distribuídos, ou tendendo à uma fileira de cada lado da nervura. Flutuadores pouco numerosos, distribuidos por toda planta; esféricos ou elípticos, com 2-3 mm de diâmetro; apiculados, ou terminados por uma expansão foliar; pedículo cilíndrico com até $8 \mathrm{~mm}$ de comprimento. Plantas dióicas. Receptáculos em grupos dicotomicamente ramificados podendo apresentar um eixo central pouco diferenciado na porção basal, produzidos na axila da folhas dos laterais primários ou nas ramificações destes. Receptáculos femininos com até $0,8 \mathrm{~cm}$ de comprimento, e masculinos, mais finos e ramificados, com até $1,3 \mathrm{~cm}$.

Material examinado: Ubatuba, P. da Fortaleza, 18/02/76, SPF 7950, $7958-7960,13 / 03 / 76$, SPF 7948, 7949, 7978-7982, 14/03/76, SPF $7976,7977,14 / 04 / 76$, SPF 7151-7955, 14/04/76, SPF 7969-7975, $17 / 04 / 76$, SPF $7956,7957,15 / 05 / 76$, SPF 7984, 29/05/76, SPF 7967, $7968,30 / 05 / 76$, SPF $7964-7966,26 / 06 / 76$, SPF $7947,15 / 12 / 76$, SPF $7961,7962,21 / 02 / 77$, SPF 7963, 04/78, SPF 7983; P. do Alto, $5 / 04 / 77$, SPF 7946.

As plantas estudadas possuem características que concordam, de uma maneira geral, com a descrição dada por Taylor (1960), exceto no que diz respeito ao comprimento máximo atingido pelas folhas. Este autor menciona que as folhas podem atingir até $15 \mathrm{~cm}$ de comprimento, o que não verificamos com as nossas.

Hoyt (1920; cf. Earle, 1969), ao contrário de Taylor (1960), inclui nesta variedade plantas com criptostomas conspicuos e abundantes.

Na Praia da Fortaleza, as plantas mais características foram coletadas no costão protegido, atiradas à praia ou crescendo a 3-4 m abaixo do limite superior da zona de $S$. cymosum var. cymosum. No local, em uma área mais rasa e restrita, ocorreram, ainda, plantas menores $(15-30 \mathrm{~cm})$, com folhas menores e mais largas, com $1,5-(3-4)-5,5 \mathrm{~cm}$ de comprimento por $2-(3-4)-7$ $\mathrm{mm}$ de largura. Estas plantas assemelham-se a $S$. vulgare, var. vulgare, mas apresentam criptostomas menos numerosos e arranjados tendendo a formar uma fileira de cada lado da nervura. Adicionalmente, apresentaram variação morfológica contínua com a variedade montagnei, da qual não podem ser separadas, tendo sido consideradas como "forma 1" por Paula (1978). Plantas muito semelhantes a 
estas, mas diferindo quanto a sexualidade dos talos (monóicas) também foram coletadas a 3-4 m de profundidade no lado batido da mesma praia. Por outro lado, plantas caracteristicamente anãs, semelhantes quanto a morfologia das folhas ocorreram nas proximidades destas últimas, crescendo em um pequeno trecho de costão batido (cerca de $50 \mathrm{~m}$ ), juntamente com S. cymosum var. nanum. Estas plantas anãs foram consideradas por paula (1978) como s. filipendula var. montagnei "forma 2". As formas 1 e 2 desta variedade não foram consideradas pelo autor como categorias taxonômicas formais em virtude da particularidade de sua ocorrência. Um reexame dessas situações sugere a possibilidade de hibridação introgressiva de $s$. filipendula var. montagnei com $S$. cymosum var. cymosum e $S$. cymosum var. nanum.

Na Praia do Alto, a variedade foi coletada apenas em pequena profundidade, juntamente com S. filipendula var. filipendula, entre outras espécies do gênero.

ral brasileiro.

Esta é a primeira referência da variedade para o lito-

8. Sargassum filipendula C. Agardh var. pinnatum Grunow Addit. Cog. Sarg., p. 170,1916 .

Bibliografia básica - Grunow 1916, p. 170 (v. pinnata), Taylor 1960 , p. 271 (v. pinnata), Earle 1969, p. 221 .

Figs. 19,42

Plantas de cor marrom-claras, enegrecendo ao secar; medindo $29-(40-50)-60 \mathrm{~cm}$ quando férteis. Laterais primários cilíndricos longos, com ramos de primeira ordem curtos e numerosos. Folhas simples a trifurcadas, planas, dispostas em espiral em torno dos eixos cilíndricos. Medem $2-(3-4)$ cm de comprimento por $2-(3-4)-6 \mathrm{~mm}$ de largura, com margem 1 isa ou provida de pequenos dentes. Flutuadores numerosos, distribuídos por toda a planta, esféricos, comumente atingindo $5 \mathrm{~mm}$, pedículo cilíndrico com (5) - $9 \mathrm{~mm}$ de comprimento. Plantas dióicas, receptáculos como na variedade típica.

Material examinado: Ubatuba, Saco da Ribeira, 15/08/62, SPF 1897; P. do Lamberto 11/07/57, SPF 1899, 12/07/76, SPF 7985-7992.

A variedade é reconhecida especialmente pelas folhas furcadas. Os espécimens aqui estudados possuem folhas mais largas que as descritas por Taylor (1960) e Earle (1969).

Foi coletada em uma única época, crescendo juntamente, com S. filipendula var. filipendula e s. filipendula var. laxum, da qual nem sempre pode ser segregada. brasileira.

Esta é a primeira referência da variedade para a costa

9. Sargassum filipendula C. Agardh var. laxum J. Agardh Sp. Algar., p. 315.1848 .

Bibliografia básica - De Toni 1895, p. 107 (como forma); Grunow 1916 , p. 170 (v. Iaxa); Taylor 1960, p. 270 (v. Iaxa); Earle 1969 , p. 221 . 
Figs . 16,44

Plantas marrom-claras quando vivas, marrom-esverdeadas a enegrecidas ao secar; medem (25-40) - $60 \mathrm{~cm}$ quando férteis. Fo1has plano-lanceoladas, simples, muito variáveis em tamanho, as mais inferiores lanceoladas com (3-4) - $6 \mathrm{~cm}$ de comprimento e (3-4) - $6 \mathrm{~mm}$ de largura; as superiores quase lineares com 1,5 (2) - $3 \mathrm{~cm}$ de comprimento e $(1-2)-3 \mathrm{~mm}$ de largura, com bordo 1 iso ou 1 igeiramente denteado. Criptostomas numerosos distribuídos irregularmente na superficie da folha. Flutuadores numerosos, distribuidos por toda planta, podem estar ausentes; com mesmas dimensões da variedade típica. Plantas dióicas, receptáculos como na variedade típica.

Material examinado: Ubatuba, Prainha (B. do Mar Virado), 4/12/76, SPF 7995-8005; P. do Lamberto (P. da Base), 15/05/76, SPF 8007, $8008,8011-8014,12 / 07 / 76$, SPF $8006,8009,8010$.

As plantas consideradas como pertencentes a esta variedade possuem as folhas dos ramos estéreis mais largas que as descritas por Taylor (1960) e Earle (1969). As plantas mais jovens poderiam ser confundidas com $s$. cymosum pelas dimensões das folhas e por possuirem bordo liso, mas distinguem-se por possuirem criptostomas numerosos, distribuídos irregularmente na superfície das folhas e ainda pelos receptáculos muito mais longos, especialmente os masculinos. E possível, por esse motivo, que $S$. filipendula var. cappanemae Grunow, referido para o Brasil (Grunow 1916), pertença a esta categoria de plantas, pois, segundo o autor, assemelha-se à s. cymosum, diferindo por possuir criptostomas mais numerosos e receptáculos mais racemosos.

Foi encontrada fértil na Praia do Lamberto e Saco da Ribeira, crescendo juntamente com $S$. filipendula var. filipendula e S. filipendula var. pinnatum e na Praia da Lagoinha e Prainha (B. do Mar Virado); aqui crescendo isoladamente.

brasileira.

Esta é a primeira referência da variedade para a costa

10. Sargassum vulgare C. Agardh var. vulgare Sp. Algar, I, P. 3 . 1820 .

Sargassum vulgare var. oxyodon e laxum Mert. Martens 1870, p. 304 .

Sargassum vulgare var. tenuifolium C. Ag. Martens 1870, p. 313.

Bibliografia básica - Martius et al. 1833 , p. 45; Martens 1870, p. 304; 1871, p. 146; Mazé e Schramm 1870-77, p. 135; Dickie 1874 , P. 375; Hemsley 1885, P. 25; De Toni 1895, p. 85; Gepp \& Gepp 1905, p. 110; Grunow 1916, p. 39; Boergesen 1914, p.62, fig, 43; Luetzelburg 1923, p. 231; Schmidt 1924; p. 90; Boergesen 1926, P. 106; Taylor 1931, p. 298; Taylor 1960, p. 272, p1. 38, fig. 1, p1.40, fig. 5; Britton \& Millspaugh 1962, p. 593; Chapman 1963, p. 41, fig. 40; Ferreira \& Pinheiro 1966, p. 62; Joly et al. 1969, p. 250; Earle 1969, p. 229; Braga 1970, p. 24; Fonseca 1973, p. 64; Ugadim 1973, p. 55; Bertossi\& Ganesan 1973, p. 14, 1am. vi, fig. 20 - 23; 01iveira Fo 1977, p. 226 . 
Figs. $20-21,32,38-39,61,72$

Plantas marrom-claras quando vivas, com pequena alteração da cor ao secar, quanto férteis medem 15-(20-30)-45 cm de comprimento. Apressório com até $1,5 \mathrm{~cm}$ de diâmetro, de onde partem ramos principais com até $3 \mathrm{~cm}$ de comprimento. Laterais primários cilindricos, 1 isos, providos de grande número de ramos de

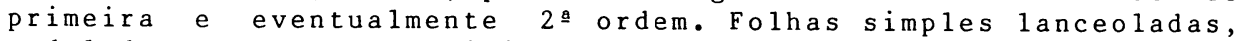
onduladas, raramente ramificadas, dispostas em espiral frouxa ou muito comprida, em ângulo aberto. Medem $1,5-(2-3)-5 \mathrm{~cm}$ de comprimento por $2-(3-5)-7 \mathrm{~mm}$ de largura; possuem margem serreada e nervura central evidente. Criptostomas muito numerosos, pequenos, irregularmente distribuídos na superfície da folha, ocorrem igualmente nos eixos cilíndricos. Flutuadores numerosos ou não, especialmente próximo à porção terminal dos ramos, podem estar ausentes em outros exemplares; esféricos, apiculados ou não, com até $3 \mathrm{~mm}$ de diâmetro; produzidos na extremidade de um pedículo cilindrico com até $5 \mathrm{~mm}$ de comprimento. Plantas dióicas ou mais raramente monóicas, oogônios e anterídios sempre em conceptáculos separados. Receptáculos em grupos dicotomicamente ramificados, podendo no entanto apresentar um eixo central pouco diferenciado nas porções basais, surgem da axila das folhas, no ápice dos laterais primários ou mais comumente nas ramificações destes. Receptáculos bissexuais e unissexuais femininos tuberculados, com até $0,7 \mathrm{~cm}$ de comprimento e os masculinos, mais finos com até $1,3 \mathrm{~cm}$.

Material examinado: Cananéia, P. de Itacuruçá ( I. do Cardoso), $01 / 59$, SPF 784; P. do Pequerê (I. do Cardoso), 28/02/64, SP 96178; P. do Pereirinha (I. do Cardoso), 23/02/64, SPF 792. Ilhabela, 1915, SP 7669, 9/02/48, SPF 1956. Caraguatatuba, P. do Capricórnio, 19/12/76, SPF 8069, 8070. Ubatuba, P. do Pulso, 4/12/77, SPF 8068; P. do Lamberto, 21/01/77, SPF 8058, 8059, 8062, 8065-8067; P. do Perequê-Mirim, 21/01/77, SPF 8064; P. da Enseada, 21/01/77, SPF 8060, 8061; Cais do Porto de Ubatuba (2), $17 / 02 / 77$, SPF 8042-8047; P. do Perequê-Açú, $12 / 02 / 77$, SPF 8039-8041; P. do A1to, 5/05/77, SPF 8056,8057; P. do Prumirim, 6/05/77, SPF 8054, 8055; P. do Ubatumirim, 6/04/77, SPF 8051-8053; P. de Picinguaba, 6/04/77, SPF 8033-8048; entre a P. de Picinguaba e P. da Fazenda, 6/04/77, SPF 8049,8050,8071.

Plantas férteis desta variedade foram encontradas em várias estações de coleta e diversas épocas do ano.

ocorrem em costões com exposição variada, predominantemente protegidos a moderadamente batidos. Os talos são muito variáveis quanto às dimensões e disposição das folhas e forma dos dentes marginais das mesmas. As folhas podem ser muito onduladas e dispostas em espiral apertada ao longo dos eixos cilíndricos, como as descritas para s. polyceratium, ou serem mais planas e dispostas em espiral mais frouxa, mesmo em exemplares que crescem 1 ado a lado (Porto de Ubatuba 2).

$\mathrm{Na}$ Praia de Monçuaba (RJ), praia localizada fora da área de concentração dos estudos, algumas plantas apresentavam oogônios em desenvolvimento nos criptostomas ligeiramente salientes das folhas normais, fato que corrobora as idéias de Simons (1906) sobre a homologia dos criptostomas e conceptáculos. 
Grunow (1916) refere para o Brasil duas variedades que não foram encontradas neste nosso trabalho. Na primeira, S. vulgare var. aspera Grunow, inclui $S$. polyphyllum Kuetzing como sinônimo. Nem a descrição dada por Grunow (1916) para esta variedade, nem a figura dada por Kuetzing (1861) para S. polyphyllum assemelham-se a qualquer das plantas por nós analisada. A segunda variedade, $S$. vulgare var. froehlichii, não pôde ser reconhecida com base na descrição dada por Grunow (1916).

As sinonímias referidas para o Brasil foram baseadas em Oliveira $F \cong(1977)$.

11. Sargassum vulgare C. Agardh var. foliosissimum (Lamouroux) J. Agardh Sp. Sarg. Austr., 108. 1889 .

Sargassum vulgare C. Ag. Jo1y 1965, p. 96. pr. IX, XIII, fig. $139-141,190$.

Bibliografia básica - De Toni 1895, p. 86 (como forma); Vickers 1908, P. 35, Pl II, fig. 1-6 (como forma); Boergesen 1914, p. 63; Grunow 1916, p. 41; Luetzelburg 1923, p. 230 (v. foliosissima); Schmidt 1924, p. 90; Taylor 1960, p. 273; Chapman 1963, p. 42, fig. 41; Earle 1969, p. 229; Bertossi \& Ganesan 1973, p. 17, 1am. VII. fig. 24-28.

Figs. 22,40

Plantas marrom-claras quando vivas, podendo tornar-se escuras ao secar; quando férteis medem $15-(20-25)-30 \mathrm{~cm}$. Apressório com até $1,5 \mathrm{~cm}$ de diâmetro, de onde partem os ramos principais em número reduzido. Laterais primários cilíndricos, lisos, com ramificação de primeira ordem. Folhas simples, lanceoladas, inseridas em espiral apertada ou não nos ramos cilíndricos. Medem 1,5 - (3-4) - 5,5 cm de comprimento por 3-(7-8) - 11 $\mathrm{mm}$ de largura, com margem irregular a serreada; nervura central evidente. Criptostomas muito numerosos, pequenos, irregularmente distribuidos na superfície da folha. Flutuadores ausentes ou numerosos e então distribuídos por toda a planta, são esféricos, com até $5 \mathrm{~mm}$ de diâmetro; pedículo cilíndricos com $1-3 \mathrm{~mm}$ de comprimento. Plantas monóicas, oogônios e anterídios localizados em conceptáculos separados ou em um mesmo conceptáculo. Receptáculos em grupos, com ramificação dicotômica, esparsa, podendo apresentar um eixo central pouco diferenciado nas porções basais, são grossos, tuberculados com até $1 \mathrm{~cm}$ de comprimento.

Material examinado: Ubatuba, P. do Lamberto (P. da Base), $11 / 07 / 61$, SPF $1955,19 / 07 / 63$, SPF $1950,14 / 05 / 76$, SPF 8072,8077 , $15 / 05 / 76$, SPF $8074-8076,12 / 07 / 76$, SPF $8073,13 / 07 / 76$, SPF 8078 .

Grunow (1961) cita S. baiense Kuetzing, referido para o Brasil por Kuetzing $(1849,1861)$ e Martens (1870) como sinonímia para esta variedade. A prancha dada por Kuetzing (1861) para $S$. baiense é incompleta para uma conclusão segura.

As descrições concordam de uma maneira geral que se trata de plantas com folhas dispostas em espiral apertada, proporcionalmente mais largas que na variedade tipo, com receptáculos mais curtos (hermafroditas segundo Grunow 1916), e protegidos 
pelas folhas. Os flutuadores podem faltar ou ser numerosos, segundo Grunow (1916) e Taylor (1960).

Plantas com essas características foram encontradas em local muito protegido (P. do Lamberto) e crescendo em convívio com a variedade tipo, S. filipendula var. filipendula, S. filipendula var.laxum e S. filipendula var. pinnatum. Foi o único táxon encontrado em local protegido com receptáculos hermafroditas.

12. Sargassum vulgare C. Agardh var. nanum v. nova

Figs. $23-24,65$

Plantae pallide castaneae in vivo, siccitate nigrescentes, fertiles 2 - (3-5) - 13 cm longae. Apressorium ad 3 cm diametro usque, ramis primariis valde reductis gaudet. Rami laterales primi ordenis laeves, exigui simplicesque. Folia simplicia lanceolata, in spiras crebes inserta ad laterales, 0,7 - (1-2) 4 cm longae, (2-3) - $4 \mathrm{~mm}$ lata; margine leviter serrulata, nervo centrali evoluto exhibentia. Cryptostomata plurima atque inordinate dispersa super folia. Organa fluitantia nulla. Stirpes monoicae; oogoniis antheridiisque in conceptaculis diversis inclusis. Receptacula globatim aggregata, glomerulis ramosis percomplanatis, foliis parviusculis tectis, in axillis foliorum directe e lateralibus primariis ortis, 0, 5 cm metientibus.

Plantas marrom-claras quando vivas, enegrecendo ao secar; medindo quando férteis $2-(3-5)-13 \mathrm{~cm}$ de comprimento. Apressorio com até $3 \mathrm{~cm}$ de diâmetro, de onde partem ramos principais muito reduzidos. Laterais primários cilíndricos, 1isos, muito curtos, não ramificados. Folhas simples lanceoladas, inseridas em espira 1 apertada nos laterais primários; medem $0,7-(1-2) 4$ $\mathrm{cm}$ de comprimento por $(2-3)-4 \mathrm{~mm}$ de largura, possuem margem serrilhada, nervura central evidente. Criptostomas numerosos e irregularmente distribuidos na superfície da folha. Flutuadores ausentes. Plantas monóicas, oogônios e anterídios em conceptáculos separados. Receptáculos em grupos ramificados, muito comprimidos, protegidos por pequenas folhas, produzidos na axila das folhas, diretamente dos laterais primários; medem $0,5 \mathrm{~cm}$ de comprimento.

Holotipo: Brasil, São Paulo, Ubatuba, P. do Flamenguinho (costão à esquerda) $16 / 12 / 76$, E.J. de Paula; E.C. de Oliveira Fo e R.P. Furtado (SPF 8089 ).

Material examinado: Guarujá, P. de Pernambuco, 21/04/76, SPF 8088; P. Branca, 9/09/76, SPF 8087. Ilhabela: 22/07/51, SPF 1937. Caraguatatuba P. do Capricórnio, 19/12/76, SPF 8086. Ubatuba: P. do Flamenguinho, 16/12/76; Ponta do Espiá, 21/01/77, SPF 8083; Porto de Ubatuba (1), 17/02/77, SPF 8081, 8082; P. do Prumirim, $6 / 05 / 77$, SPF 8080 ; P. de Picinguaba, 6/04/77, SPF 8079 .

Nesta variedade foram incluidas plantas anãs com indiscutível afinidade morfológica com S. vulgare var. vulgare, reconhecida especialmente pelas dimensões e forma das folhas e distribuição dos criptostomas. 
As plantas foram encontradas em 9 estações de coleta, em costões extremamente batidos. Sempre formando uma faixa estreita, em nível elevado do costão e inteiramente expostas a o ar nas marés mais baixas. Em alguns locais também foi encontrada a variedade tipo, mas, nestes casos, as duas populações achavam-se separadas por uma extensão do costão muito pobre em algas. Nas Praias do Flamengo, Flamenguinho, Itaguá, Fazenda, Picinguaba e Ponta do Espiá, por exemplo, as populações de $S$. vulgare var. vulgare e $S$. vulgare var. nanum estavam separadas por uma extensão de costão onde apenas coralináceas incrustantes e eventualmente ouriços, em grande quantidade, eram praticamente os únicos elementos presentes.

As diferenças morfológicas destas plantas, com relação à variedade tipo, sua ocorrência em várias estaçóes de coleta e o isolamento de suas populaçóes sugere divergência genética de populações localmente adaptadas (ecótipo), como no caso de $S$. cymosum var. cymosum e S. cymosum var. nanum. Estudos experimentais de cultivo em laboratório (Paula 1984) corroboram esta interpretação.

13. Sargassum furcatum Kuetzing Sp. Algar,. p. 616. 1849

S. diversifolium Ag. Taylor 1960, P. 282 e Oliveira Fo 1977, p. 334 (como referência duvidosa).

Bibliografia básica - Kuetzing 1861, p. 10, t. 32 II; Taylor 1960 , p. 277 ; Mazé \& Schramm 1970-77, p. 135; Díaz-Piferrer 1970, P. 169 , fig. 19 .

Figs . 25-26, 33-37, 62, 66, 73

Plantas marrom-claras quando vivas, podendo tornar-se escuras ao secar; quando férteis medem $10-(15-20)-30 \mathrm{~cm}$ de comprimento. Apressório com até $1,5 \mathrm{~cm}$ de diâmetro, de onde partem ramos principais muito reduzidos. Laterais primários cilíndricos, ligeiramente achatados em determinadas porções, com projeções espiniformes em toda extensão ou em parte lisos; providos de ramificações de primeira e segunda ordem. Folhas ramificadas, podendo, especialmente as inferiores, ser simples, linear-lanceoladas, comumente onduladas inseridas nos ramos cilíndricos em ângulo aberto. Medem 1 - (2-3) - 4,5 cm de comprimento e 2 - (3-4) - $8 \mathrm{~mm}$ de largura; as maiores, pouco numerosas, ocorrem próximas ao apressório, possuem margem serreada e nervura central evidente. Criptostomas muito numerosos, irregularmente distribuidos na superfície da folha, com diâmetro muito variável, os menores mais marginais; ocorrem ainda nos flutuadores e nos ramos cilíndricos; aqui são alongados, ligeiramente salientes ou ocorrem sobre projeções espiniformes. Flutuadores numerosos, ocorrendo próximo ao ápice ou distribuidos por toda a planta; podem estar ausentes. São esféricos, às vezes terminados por uma expansão foliar; medem até $4 \mathrm{~mm}$ de diâmetro, sendo produzidos na extremidade de um pedículo cilíndrico, levemente achatado ou expandido em forma de fo$1 \mathrm{haj}$ medem 2 - $(3-4)-5 \mathrm{~mm}$ de comprimento. Plantas monóicas ou dióicas, oogônios e anterídios sempre em conceptáculos separados. Receptáculos em grupos dicotomicamente ramificados, na axila das folhas do lateral primário ou mais comumente das ramificaçós 
destes; protegidos por pequenas folhas e "escondidos" pelas fothas maiores, em raros casos providos de "espinhos". Receptáculos bissexuais irregularmente tuberculados; os espaços lisos ocupados por conceptáculos masculinos, com até 0,7 cm; receptáculos femininos tuberculados e os masculinos 1 isos, mais finos, ambos com cerca de $0,8 \mathrm{~cm}$.

Material examinado: São Sebastião, P. de Pauba, 9/10/76, SPF 7936, 14/12/77, SPF 7586, P. de Santiago, 9/10/76, SPF 7588, 14/12/77, SPF 7585; Entre P. do Toque-Toque Pequeno e P. de Santiago, $9 / 10 / 76$, SPF 7587; P. de Barequeçaba, 20/01/76, SPF $7562-7564,8 / 10 / 76$, SPF 7560, 7561,8018,8019; P. do Segredo, $12 / 07 / 76, \quad \mathrm{SPF} 7576,7577,7580,7581,8017$; P. do Cabelo Gordo, $30 / 05 / 76$, SPF 7582, 7583, 19/05/77, SPF 7572, 7579, 6/12/77, SPF 7559 ; P. Grande, 19/05/77, SPF 7571, 7573,7574; P. do Araçá, 20/01/76, SPF 7565. I lhabe1a, 1915, SP 7667, 7668, sem data, SP $7670,8 / 9 / 1925, \quad S P 33393,8-9 / 1925$, SP 33407; P. dos Barreiros, 14/12/77, SPF 7584. Ubatuba, P. do Junqueira, 16/12/76, SPF 7566-7568; P. da Enseada, 21/01/77, SPF 7569 .

S. furcatum foi referido como variedade de $S$. vulgare por Grunow (1916) e Boergesen (1926) e como uma forma desta espécie por De Toni (1895). Outros autores reconhecem o táxon na categoria de espécie, sendo segregado de $S$. vulgare especialmente pelas folhas ramificadas e eixos cilíndricos muriculados. Verificamos que o grau ou freqüência destes caracteres variam de espécime para espécime e entre populações diferentes. Mesmo nas populações mais características alguns exemplares podem apresentar uma baixa freqüência de folhas ramificadas, ou somente folhas simples e eixos cilíndricos parcial ou totalmente lisos. Nas situações mais extremas estes exemplares não podem ser distinguidos de S. vulgare var. vulgare, mas, em geral, a presença de uma ou de outra característica é auxiliar na identificação. De qualquer maneira, verifica-se, nestes casos, uma variação morfológica contínua com as plantas mais características. Populações de S. vulgare, por outro lado, podem apresentar alguns exemplares com baixa freqüências de folhas ramificadas. Estas observações sugerem uma afinidade entre dois táxons. Considerando-se, em conjunto, as dificuldades na delimitação das espécies em geral, mantivemos o tratamento taxonômico a nível específico, como na literatura recente.

Algumas populações analisadas apresentaram características que concordam com a descrição de Grunow (1916) para S. vulgare var. furcatum f. humilis, citado para as Ilhas Canárias, Madeira Grande, Salvage e Açôres. Diferem pelas folhas menores, quase lineares, com bordo liso ou ligeiramente serreado e criptostomas maiores, pouco numerosos, irregularmente distribuídos ou tendendo a formar uma fileira de cada lado da nervura. Nestas populações ocorreram plantas exclusivamente dióicas.

Nos locais de coleta muito batidos, por outro 1 ado, ocorreram populações de plantas caracteristicamente añas, muito uniformes quanto ao comprimento do talo, com $3-(4-7)-11 \mathrm{~cm}$ de comprimento e crescendo em nível elevado do costão, formando faixas verticalmente estreitas. Apresentavam folhas muito variáveis, desde linear-1anceoladas, simples ou ramificadas, com $2-3 \mathrm{~cm}$ de comprimento por $2-(3-4)-5 \mathrm{~mm}$ de largura, com bordo 1 iso ou 
serreado. Criptostomas e eixos cilíndricos são como nos casos anteriores. Nestas populações ocorreram plantas monóicas e raras unissexuais masculinas, com receptáculos mais comprimidos que as plantas de local protegido. Foram encontradas em 4 estaçóes de coleta, sempre isoladas das populações de plantas caracteristicamente maiores, mesmo quando presentes na mesma área como na praia de Pauba, onde estas últimas ocorreram em maior profundidade, mas ambas separadas por uma zona muito pobre em algas em geral. Isto sugere que estas populações correspondem a um ecótipo anão, como no caso de $S$. cymosum var. nanum e $S$. vulgare var. nanum.

As caracteristicas destas plantas anãs concordam com a descrição de Grunow (1916) para S. vulgare var. lanceolataf. diversifolia, citado para as Ilhas Canárias, Açores e Madeira. Boergesen (1926) descreve em maior detalhe esta forma de Grunow, mencionando que as plantas não ultrapassam $10 \mathrm{~cm}$ de comprimento e que os espécimes por ele analisados não apresentavam flutuadores e encontravam-se estéreis. De acordo com este autor deve ser vista como uma forma reduzida e adaptada a locais expostos, sugerindo que devam ser incluídas na "forma humilis" mencionada acima. Algumas das plantas analisadas assemelharam-se a figura de Kuetzing (1861) para $S$. diversifolium, especialmente os espécimes com poucas folhas furcadas e com bordos lisos, razão pela qual inclui-se esse binômio como sinonímia.

As combinações, $S$. furcatum Kuetzing var. humilis (Grunow) Paula e S. furcatum Kuetzing var. diversifolium (Grunow) Paula, propostas como novas por Paula (1978), para as formas de Grunow mencionadas acima, necessitam de um reexame com base em estudos experimentais e estudos em uma escala geográfica mais ampla, ao lado de estudos do material tipo, para um julgamento mais criterioso.

E comum nesta espécie o encontro de partes dos receptáculos transformados em folhas e vice-versa.

Ésta a primeira referência documentada da espécie para o litoral brasileiro.

\section{DISCUSSÃo}

As espécies abrangidas no presente trabalho pertencem "sensu" Grunow ao subgênero Eusargassum, série Malacocarpicae, estando distribuidas em duas tribos: I Cymosae e I I Racemosae; caracterizadas com base na morfologia dos receptáculos. De acordo com Grunow, $S$. filipendula estaria incluido na tribo Racemosae, enquanto todas as outras espécies analisadas pertenceriam a tribo Cymosae. Com base na análise das plantas estudadas as diferenças atribuidas as duas tribos não parecem satisfatórias, como sugerido por Setchell (1936).

A morfologia e especialmente a sexualidade dos receptáculos não foi considerada por Taylor (1960) e pelos autores que o seguiram no estudo das espécies do At lântico Americano. Grunow (1915, 1916) refere-se ao gênero como possuindo espécies sub-dióicas (ou poligâmicas) e dióicas ou hermafroditas, mas não garante que os últimos casos o sejam exclusivamente. Setchell (1936), da mesma maneira, supõe que muito poucas espécies sejam estritamente dióicas. Yoshida (1983), por outro lado, refere-se as espécies do subgênero Bactrophycus, como sendo, em sua maioria 
dióicas, enquanto poucas são monóicas ou de espressão sexual variáve 1 .

Os dados sobre o sexo dos talos fornecidos por Grunow (1916), para alguns táxons que estudamos, nem sempre concordam com os nossos resultados. Simons (1906) cita a ocorrência de conceptáculos uni ou bissexuais para s. filipendula, enquanto para a nossa região apenas conceptáculos unissexuais foram verificados.

De acordo com Grunow (1915, 1916), Setchell (1936), Tsuda (1972), o dimorfismo sexual dos receptáculos parece ter sido a causa de algumas identificações errôneas.

Para as espécies estudadas, a morfologia e sexualidade dos receptáculos mostraram-se de um valor taxonômico relativo, devendo ser consideradas em conjunto com as outras caracteristicas. São elucidativas, sobretudo, com relação as variações fenotípicas associadas ao grau de exposição as ondas.

As respostas do fenótipo ao ambiente são freqüentemente mais marcadas entre espécies de algas perenes que nas anuais, sendo uma das fontes das dificuldades taxonomicas verificadas entre os membros das Fucales (Russell 1978). A variabilidade exibida por representantes do grupo tem sido referida comumente como "plasticidade", embora sua natureza não seja conhecida (Evans et al 1982). Russel (1978) sugeriu que as variaçós fenotípicas no gênero Fucus devem ser, em parte, o resultado da seleção natural, através da exposição as ondas, entre outros fatores que operam no genótipo que coloniza um determinado ambiente. A natureza e variabilidade desses genótipos dependeria, ainda, do fluxo gênico entre populações adjacentes.

No caso específico das populações de sargassum estudadas, a interpretação de Russel é corroborada pelas acentuadas modificaçós morfológicas que se verificam ao longo do gradiente horizontal de exposição as ondas, especialmente se considerarmos as diferenças da morfologia e sexualidade dos talos, que certamente podem ser atribuidas a diferenças genotípicas. Estudos experimentais de transplante (Paula \& Oliveira Fo 1982) e de cultivo em laboratório (Paula 1984), reforçam esta interpretação. Neste sentido, $S$. cymosum var. cymosum e S. vulgare var. vulgare podem ser consideradas espécies predominantemente dióicas, enquanto as variedades anãs atribuídas a essas espécies, predominantemente monóicas, pelo menos para a região estudada. As variações desses casos podem ser atribuídas ao fluxo gênico.

A ocorrência de 13 táxons infragenéricos de sargassum para o litoral do Estado de São Paulo, documentada no presente trabalho, contrastando com 5 referidos anteriormente, refleteo estado atual do conhecimento da taxonomia do gênero.

0 gênero está representado no At lântico Americano por 17 espécies, se considerarmos 14 reconhecidas por Taylor (1960) e incluirmos $S$. wolfii Earle e $S$. pusillum Taylor, descritas mais recentemente (Earle 1969, Taylor 1975) e S. stenophyllum na categoria de espécie (Taylor 1976). Dentre estas, Oliveira Fo (1977) considerou 9 validamente para o Brasil, tendo incluido s. ramifolium como referência duvidosa e não mencionando S. furcatum, ambas verificadas no presente estudo. De uma maneira geral, as referências novas para a região estudada devem-se, basicamente, a uma coleta mais numerosa e abrangente. Com exceção das variedades anãs de $S$. cymosum e S. vulgare, todas as outras espécies e variedades reconhecidas para o litoral de São Paulo estão representadas na região do Caribe e Golfo do México. 
A categoria de espécie ou variedade atribuída por diferentes autores para $S$. stenophyllum ( $S$. cymosum var. stenophyllum), S. ramifolium (s. cymosum var. ramifolium) e s. furcatum (S. vulgare var. furcatum) reflete as dificuldades na delimitação das espécies, mencionadas anteriormente. As diferentes categorias taxonômicas atribuídas nestes casos sugerem a subjetividade dos critérios adotados por diferentes autores e, ou, diferentes graus de variação entre as amostras analisadas. Nesse particular, o litoral do Estado de São Paulo situa-se próximo ao limite sul de distribuição do gênero no Atlântico Americano, podendo-se esperar para a região um grau de variabilidade e problemas taxonômicos próprios. Considerando-se possíveis variações em uma escala geográfica mais ampla, preferimos, nestes casos, adotar os critérios da literatura recente para a região.

Agradecimentos: Ao Dr. Carlos Toledo Rizzini, pela preparação da diagnose latina, ao Dr. Antonio Salatino, pela colaboração prestada na preparação do texto em língua inglesa. A Fundação de Amparo à Pesquisa do Estado de São Paulo, FAPESP (Processo: 04 - Biológicas 76/0164) e ao Conselho Nacional de Desenvolvimento Científico e Tecnológico, CNPq (Processo: 105-301130/83), pelos auxílios concedidos que permitiram a realização deste trabalho.

\section{REFERENCIAS}

AGARDH, C.A. 1820. Species Algarum rite cognitae, cum synonimis, differentiis specificis et descriptionibus succintis. vol. 1. Ex Officina Berlingiana, Lund.

AGARDH, C.A. 1824. Systema Algarum. Literis Berlingianis. Lund.

AGARDH, J.C. 1848. Species genera et ordines Algarum. vol. 1. C.W.K. Gleerup. Lund.

AGARDH, J.C. 1889. Species Sargassorum Australieae. K. svenska Vetenska Akad. Hand1. 23: 1-133.

BAPTISTA, L.R.M. 1974. Flora marinha de Torres (Rio Grande do Sul). Tese de Livre-Docência. Univ. Fed. do Rio Grande do Sul. Porto Alegre.

BERTOSSI, S.A. \& GANESAN, E.K. 1973. E1 genero Sargassum C. Agardh (Feofita) en oriente de Venezuela. Lagena 31: 3-22.

BOERGESEN, F. 1914. The marine algae of the Danish West Indies. Part II, Phaeophyceae. Dansk. bot. Ark., Kjobenhavn 2: 1-68.

BOERGESEN, F. 1926. Marine algae from the Canary Islands especially from Teneriffe and Gran Canaria. II. Phaeophyceae. K. Dansk. Vidensk. Selsk. Biol. Meddel., Kjobenhavn 6: 1-112.

BOROJEVIC, R. 1971. Eponges calcaires de côte sud-est du Brésil, épibiontes sur Laminaria brasiliensis et Sargassum cymosum. Rvta. bras. Biol. 31: 525-530.

BRAGA, Y.Y. 1970. Flora marinha bentônica da Baía de Guanabara e cercanais. II - Phaeophyta. Publ. Inst. Pesq. Marinha 45: 1-31.

BRITTON, N.L. \& MILlSPAUGH, C.F. 1962. The Bahama flora. Hafner Publishing. New York.

CHAPMAN, V.J. 1963. The marine algae of Jamaica. Pheophyceae and Rhodophyceae. Bull. Inst. Jamaica Sci ser. 12(2): 1-201. 
COLLINS, F.S., HOLDEN, I. \& SETCHELL, W.A. 1905. Phycoteca Boreali Americana. A. collection of Dried specimens of the Algae of North America. Fasc. D., exsicata 97.

COSTA, H.R. da la 1962. Note preliminaire sur les peuplements intercotidaux de substrat dur du littoral de Rio de Janeiro. Recl. Trav. Stm. mar. Endoume 26: $197-207$.

CRUZ, 0. 1974. A Serra do Mar e o litoral na área de Caraguatatuba, contribuição a geomorfologia tropical litorânea. Inst. Geogr., Univ. S. Paulo. São Paulo.

DAVIS, P.H. \& HEYWOOD, V.W. 1973. Principles of Angiosperm taxonomy. Robert E. Krieger Pub1. Co. New York.

DE TONI, J.B. 1895. Sylloge algarum oninium hucusque cognitarum. vol. 1. Typis Seminarri. Padua.

DE WREEDE, R.E. \& JONES, E.C. 1973. New records of Sargassum hawaiensis Doty an Newhouse (Sargassaceae, Phaeophyta), a deep water species. Phycologia la 12: $59-62$.

DfAZ PIFERRER, M. 1970. Adiciones a la flora marina de Venezuela. Carib. j. SCi. 10: 159-198.

DICKIE, G. 1874. Ennumeration of algae collected from 30 fathons at Barra Grande, near Pernambuco, Brazil. J. Linn. Soc. Bot. 14: 375-376.

DUNAL, F. 1833. Revision Bibliographique de A. de Saint Hilaire, "Voyage dans le District des Diamans et sur le littoral du Brésil...". Arch. Bot. 2: 444-456.

EARLE, S. 1969. Phaeophyta of the Eastern Gulf of Mexico. Phycologia 7: $71-254$.

EMILSSON, I., GARCIA OCCHIPINTI, A., KUTNER, A.S., MINIUSSI, I.C.\& VANNUCCI, M. 1963. Levantamento oceanográfico-meteorológico da Enseada do Mar Virado - Ubatuba, Estado de São Paulo. Contrções. Inst. Oceanogr. Univ. S. Paulo 5 : $1-118$.

EVANS, L.V., CALLOW, J.A.\& CALLOW, M.E. 1982. The biology and biochemistry of reproduction and early development in Fucus. In F.E. Round \& D.J. Chapman (ed.)Progress in phycological research. vol. 1. Elsevier Biomedical Press, P. 68-110.

FERREIRA, M.M. \& PINHEIRO, F. 1966. Primeira contribuição ao inventário das algas marinhas bentônicas do $\mathrm{NE}$ brasileiro. Archos Est. Biol. mar. Univ. Fed. Ceará 6: 59-66.

FONSECA, M.C. de A. 1973. Algumas espécies de algas marinhas de Pernambuco. In D. Andrade-Lima (ed) XIII Congresso Nacional de Botânica. Editora Universitária, Recife, p. 61-74.

FRITSCH, F.E. 1945. The structure and reproduction of the algae. vo1. 2. University Press. Cambridge.

GEPP, A. \& GEPP, E.S. 1905. Atlantic algae of the "Scotia". J. Bot., London 43 :109-110.

GRUNOW, A. 1915. Additamenta ad cognitionem Sargassorum. Verh. zool-bot. Ges. 65: 329-448.

GRUNOW, A. 1916. Additamenta ad cognitionem Sargassorum. Verh. zool-bot. Ges. 66: $1-48,136-185$.

HEMSLEY, W.B. 1885. Algae. In Report on the Botany of Bermudas and various other islands of the Atlantic and Southern Oceans. Rep. Sci. Res. Exploring Voyage of H.M.S. "Challenger", 1873-1876. Botany 1: 104-128.

HOWE, M.A. 1928. Notes on some marine algae from Brazil and Barbados J. Wash. Acad. Sci. 18: 186-194.

JENSEN, J.B. 1974. Morphological studies in Cystoseiraceae and Sargassaceae (Phaeophyceae), with special reference to apical organization. Univ. Calif. Publis. Bot. 68: 1-61. 
JOLY, A.B. 1951. Contribuição para o conhecimento da flora algológica do Estado do Paraná. Bolm Inst. paul. Oceanogr. 2: 125-138.

JOLY, A.B. 1957. Contribuição ao conhecimento da flora ficológica marinha da Baía de Santos e arredores. Bolm Fac. Filos. Ciênc. Univ. S. Paulo, ser. Bot. 14: 1-196.

JOLY, A.B. 1965. Flora marinha do litoral Norte do Estado de São Paulo e regiões circunvizinhas. Bolm Fac. Ciênc. Univ. S. Paulo, ser. Bot. 21: 1-393.

JOLY, A.B., OLIVEIRA Fo, E.C. de \& NARCHI, W. 1969. Projeto de um Parque Nacional Marinho na região de Abrolhos, Bahia. Anais Acad. bras. Ciênc. 41 (sup1.): 247-251.

KUETZING, F.T. 1843. Phycologia generalis; oder Anatomie, Physiologie and Systemkund der Tange. F.A. Brockhaus, Leipzig.

KUETZING, F.T. 1849. Species Algarum. F.A. Brockhaus. Leipzig.

KUETZING, F.T. 1861. Tabulae phycologicae, oder Abbildungen der Tange. v. 11. Kosten des Verfassers. Nordhaufen.

KUTNER, M.B. 1961. Algumas diatomáceas encontradas sobre algas superiores. Bolm Inst. Oceanogr. Univ. S. Paulo. 11: 3-13.

KVINGE, T. 1967. On the special current and water level variations in the channel of São Sebastião. Bolm Inst. Oceanogr. Univ. S. Paulo. 16: 23-38.

LIMA, H.S. 1969. Fauna séssil do Sargassum cymosum da Praia do Lamberto, Ubatuva (Estado de São Paulo), Composição qualitativa e considerações sobre a localização das espécies na planta. Dissertação de Mestrado. Inst. Bioc., Univ. S. Paulo. São Paulo.

LUETZELBURG, P. von 1923. Estudo botânico do Nordeste. Publções Inspetorial Federal de Obras Contra as Secas 57(3): 227-231.

MARTENS, G. von 1870. Conspectus algarum Brasiliae hactenus detectarum. Vidensk. Meddr dansk. Naturh. Foren. 2: 287-314.

MARTENS, G. von 1871. Algae brasiliensis circa Rio de Janeiro. A c1. A. Glaziou, horti publici directore, botanico indefesso, annis 1869 et 1870 collectae. Vidensk. Meddr dansk. Naturh. Foren. 144-148.

MARTIUS, K.F.P. von, ESCHWEULLER, F.C. \& ESENBECK, C.G.N. von. 1833. Flora Brasiliensis seu enumeratio plantarum in Brasilia. vol. 1. Sumptibus J.G. Cottae. Stuttgart.

MARTIUS, K.F.P. von 1828-34. Icones Plantarum Cryptogamicarum quas in itinere annis 1817-1820 per Brazilian. Impensis Auctoris. Monacchii.

MATTOS, A. de 1952. Notas sobre algas do litoral Paranaense. Archos Mus. parana 9: 245-260.

MAZE, H. \& SCHRAMM, A. 1870-77. Essai de classification des algues de la Guadaloupe. Imprimerie du Governement, Basse-Terre.

MOEBIUS, M. 1889. Bearbeitung der von H. Shenk in Brasilien gesammelten Algen. Hedwigia 28: 309-347.

MOEBIUS, M. 1890. Algae Brasiliensis A. c1. Dr. Glaziou collectae. Notarisia 5 : $1065-1090$.

MOEBIUS, M. 1892. Ueber einige Brasilianishe Algen. Bern. schweiz. bot. ges. 10: $17-26$.

MONTAGNE, J.F.C. 1839. Cryptogamae Brasiliensis seu plantae cellulares quas in itinere per Brasiliam à céleb. Auguste de Saint-Hilaire collectas recensuit observationibusque nonnulis ilustravit. Annls Sci. nat. bot. 12. 42-44.

MOREIRA Fo, H. 1959. Diatomáceas do Paraná. I - A Flora diatomológica no Sargassum. Bolm Inst. Hist. Nat., I, Bot. 2: 1-27.

MOREIRA Fo, H. \& OLIVEIRA Fo, E.C. 1976. Diatomáceas epífitas em duas populações de Sargassum cymosum C. Ag. Acta Biológica Paranaense 5: 53-75.

MOUNTOUCHET, P.E.G. 1979. Sur la communauté des animaux vagiles associés à Sargassum cymosum C. Agardh, à Ubatuba, Etat de São Paulo, Brésil. Stud. netrop. Fauna Environm. 14: 33-64. 
NIZAMUDDIN, M. 1962. Classification and the distributioin of the Fucales. Botanica mar. 4: 191-203.

NIZAMUDDIN, M. 1970. Phytogeography of the Fucales and their seasonal growth. Botanica mar. 13: 131-139.

NONATO, E.F. \& PÉREs, J.M. 1961. Observations sur quelques peuplements intertidaux de substrat dur dans la régions d'Ubatuba (État de S. Paulo). Cah. Biol. mar. 2: 263-270.

OKUDA, T., KAREI, H. \& YAMADA, M. 1984. Settlement of germlings in ten Fucales species. In C.J. Bird \& M.A. Ragan (ed.) XI International Seaweed Symposium. Junk Publishers, Qindao, p. 413-418.

OLIVEIRA Fo, E.C. de. 1977. Algas marinhas bentônicas do Brasil. Tese de Livre-Docência. Inst. Bioc., Univ. S. Paulo. São Paulo.

OLIVEIRA Fo, E.C. de \& MAYAL, E.M. 1976. Seasonal distribution of intertidal organisms at Ubatuba, São Paulo (Brazil). Revta bras. Biol. 36: 305-316.

OLIVEIRA Fo, E.C. de \& PAULA, E.J. de 1979. Potentiality for algin production in the São Paulo (Brazil) littoral region. In A. Jensen \& J.R. Stein (ed.) IX International Seaweed Symposium. Science Press, S. Barbara, p. 479-486.

PARR, A.E. 1939. Quantitative observations on the pelagic Sargassum vegetation of the Western North Atlantic. Bull. Bingham Oceanogr. Coll. 6: 1-94.

PAULA, E.J. de 1978. Taxonomia, aspectos biológicos e ecológicos do gênero Sargassum (Phaeophyta - Fucales) no litoral do Estado de são Paulo. Dissertação de Mestrado. Inst. Bioc., Univ. S. Paulo. São Paulo.

PAULA, E.J. de 1984. Estudos experimentais de cultivo e hibridação em Sargassum (Phaeophyta - Fucales) em condições de laboratório. Tese de Doutorado. Inst. Bioc., Univ. S. Pauło. São Paulo.

PAULA, E.J. de \& 01iveira Fo, E.C. de 1980. Aspectos fenológicos de duas populações de Sargassum cymosum (Phaeophyta - Fucales) do litoral de São Paulo, Brasil. Bolm Botânica, Univ. S. Paulo 8: 21-39.

PAULA, E.J. de \& OLIVEIRA Fo, E.C. de 1982. Wave exposure and ecotypical differentiation in Sargassum cymosum (Phaeophyta - Fucales). Phycologia 21 : 145-153.

PEREIRA-LEITE, F.P.P. 1976. Estadios de crescimento e aspectos da reprodução de Hyale medi (Crustaceae - Amphipoda, Hyalidae) de Fauna vágil de Sargassum cymosum. Dissertação de Mestrado. Inst. Oceanogr., Univ. S. Paulo. São Paulo.

PICCONE, A. 1886. Alghe del viaggio di circumnavigazione della "Vettor Pisani". Notarisia 1(5): 283-287.

PICCONE, A. 1889. Nuove alghe del viaggio di circumnavigazione della "Vettor Pisani". Atti R. Accad. Lince, Memoire Cl. Sci. Fisiche, Mat. e Nat. 6: 10-63.

PIRES, A.M.S. 1975. Sobre a Biologia de Janaira gracilis (Crustaceae, Isopoda, Asellota) da Fauna vágil de Sargassum cymosum. Dissertação de Mestrado. Inst. Oceanogr., Univ. S. Paulo. São Paulo.

RAWITSCHER, F. 1944. Algumas noções sobre a vegetação do 1itoral brasileiro. Bolm Ass. Geogr. bras. 5: 13-28.

ROCHA-OLIVEIRA, I. da 1980. Distribuição das diatomáceas epîfitas na região de Ubatuba. Dissertação de Mestrado. Inst. Oceanogr., Univ. S. Paulo. São Paulo.

RUSSEL, G. 1978. Environment and form in the discrimination of taxa in brown algae. In D.E.G. Irvine \& J.H. Price (ed.). Modern appoaches to the taxonomy of red and brown algae. Academic Press, London, p. 339-370.

SAINT-HILAIRE, A. 1833. Voyage dans le district des Diamants et sur le littoral du Brésil. vol. 2. Librairie-Gide, Paris.

SCHMIDT, O.C. 1924. Meeresalgen der Sammlug von Luetzelburg aus Brasilien. Hedwigia 65: 85-100.

SETCHELL, W.A. 1931. Hong Kong Seaweeds. II. Hongkong Nat. 2: 237-253. 
SETCHELL, W.A. 1933. Hong Kong Seaweeds. III. Sargassaceae. Hongkong Nat. 2: 33-49.

SETCHELL, W.A. 1935. Hong Kong Seaweeds. IV. Sargassaceae. Hongkong Nat. 4: $1-24$.

SETCHELL, W.A. 1936. Hong Kong Seaweeds. V. Sargassaceae. Hongkong Nat. 5: $1-20$.

SILVA, P. de C.M. 1952. Estudo preliminar da propagação do marulho na costa do Estado de São Paulo. Bolm Inst. Oceanogr. 3: 35-38.

SIMONS; E.B. 1906. A morphological study of Sargassum filipendula. Bot. Gaz. 41: $161-182$.

TARARAM, A.S. \& WAKABARA, Y. 1981. The mobile fauna - especialy Gammarideae of Sargassum cymosum. Mar. Ecol. 5: 157-163.

TAYLOR, W.R. 1930a. Algae collected on the Hassler, Albatross and Schmidt Expeditions: I. Marine Algae from Brazil. Am. J. Bot. 16: 627-634.

TAYLOR, W.R. 1930b. Note on marine algae from São Paulo, Brazil. Am. J. Bot. 17: 635 .

TAYLOR, W.R. 1931. A synopsis of the marine algae of Brazil. Revue algol. 5: 279-313.

TAYLOR, W.R. 1960. Marine Algae of the Eastern Tropical and Subtropical coast of the Americas. The University of Michigan Press. An Arbor.

TAYLOR, W.R. 1975. A pelagic Sargassum from the Western Atlantic. Contr. Univ. Mich. Herb. 11: 73-75.

TAYLOR, W.R. 1976. A check list of Venezuelan Marine Algae. Bolm Soc. Venez. de Cienc. Nat. 22: 132-133.

TSUDA, R.T. 1972. Morphological, zonational and seasonal studies on two species of Sargassum on the reefs of Guam. In K. Nisizawa (ed.) VII International Seaweed Symposium University of Tokyo Press, Sapporo, p. 40-44.

TSUKIDATE, T. 1984. Studies on the regenerative ability of the brown algae, Sargassum muticum (Yendo) Fensholt and Sargassum tortile C. Agardh. In C.J. Bird \& M.A. Ragan (ed.) XI International Seaweed Symposium. Dr. W. Junk Publishers, Qingdao, p. 393-397.

UGADIM, Y. 1973. Algas marinhas bentônicas do litoral sul do Estado de São Paulo e do litoral do Estado do Paraná. II. Divisão Phaeophyta. Port. Acta. biol. ser. B. 12: 69-131.

UMEZAKI, I. 1984. How many eggs will be discharged from the plant of Sargassum horneri? In C.J. Bird \& M.A. Ragan (ed.) XI International Seaweed Symposium. Dr. W. Junk Publishers, Qindao, p. 388-402.

VICKERS, A. 1908. Phycologia barbadensis IConographie des algues récol tées a L'Ile Barbade (Antilles) (Chlorophycées et Pheophycées). Pt. 2. Librairie des Science Naturelles. Paris.

WILLIAMS, L.G. \& BLOMQUIST, H.L. 1947. A collection of marine algae from Brazil. Bull. Torrey bot. Club. 74: 383-397.

WOMERSLEY; H.B.S. 1954. Australian species of Sargassum, subgenus Phyllotrichia. Aust. J. Bot. 2: 337-354.

YAMAUCHI, K. 1984. The formation of Sargassum beds on artificial substrata by transplanting seedlings of $S$. horneri (Turner) $C$. Agardh and $S$. muticum (Yendo) Fensholt. Bull. Jap. Soc. Scient. Fish. Tokyo 50: 1115-1123.

YOSHIDA, T. 1983. Japanese species of Sargassum subgenus Bactrophycus (Phaeophyta, Fucales). J. Fac. Sci Hokkaido Univ. ser. V (Botany) 13: 99-246.

ZELLER, G. 1876. Algae Brasiliensis circa Rio de Janeiro a Dr. Glaziou, Horti Publici Diretore Collectae. Vidensk. Medd. Naturh. Foren. Kjobenhavn 22: 426-432. 